\title{
A Parametric Study and Performance Evaluation of Energy Retrofit Solutions for Buildings Located in the Hot-Humid Climate of Paraguay-Sensitivity Analysis
}

\author{
Fabiana Silvero ${ }^{1,2, *(\mathbb{C})}$, Fernanda Rodrigues ${ }^{1(\mathbb{D})}$ and Sergio Montelpare ${ }^{2}$ (i) \\ 1 RISCO, Civil Engineering Department, University of Aveiro, 3810-193 Aveiro, Portugal; mfrodrigues@ua.pt \\ 2 Geology and Engineering Department, University G. d'Annunzio of Chieti-Pescara, 42-65127 \\ Chieti-Pescara, Italy; s.montelpare@unich.it \\ * Correspondence: fabiana.silvero@unich.it; Tel.: +595975123668
}

Received: 14 December 2018; Accepted: 24 January 2019; Published: 29 January 2019

check for updates

\begin{abstract}
Nowadays, awareness concerning the need to use energy efficiently is increasing significantly worldwide, thus, improving the energy efficiency levels in the building sector has acquired high importance because of their energy saving potential. However, several intervention options are available to achieve high energy efficiency levels in buildings, and the choice must be made considering the efficiency of the solution and the costs involved. Considering this, the present research aimed to develop a parametric study of several energy retrofit solutions for buildings located in the hot-humid climate of Paraguay, in order to analyse their efficiency in terms of comfort rates and cooling energy needs. Furthermore, the Analytic Hierarchy Process (AHP) is employed as a decision-making method to choose the most suitable intervention considering the investment costs required. Thus, threshold values of thermal transmittance for the building thermal envelope components are established through a parametric study and sensitivity analysis of the simulations results. Considering that Paraguay does not have national building energy codes, the outcomes of this research will constitute a support and contribute for the thermal parameters regulation of buildings aiding to improve the energy efficiency of Paraguayan buildings.
\end{abstract}

Keywords: energy retrofit solutions; buildings energy efficiency; energy requirement; AHP

\section{Introduction}

Currently, strategies to optimise buildings' energy efficiency (EE) have become of outstanding importance. The architectural characteristics of buildings and physical properties of materials, such as thermal resistance, structural material, thermal mass, the orientation and shape, are some of the most important parameters influencing buildings' thermal performance [1]. The use of thermal insulation materials for the building envelope components is one of the most often used methods to improve their thermal performance. In fact, in order to accomplish the EE requirements set in the regulations and energy codes of several countries, the use of these materials has increased significantly in the last years [2].

The referred standards set specific parameters for the buildings' envelope components in order to attain thermal comfort inside the building with lower energy expenditure. Some of the most used parameters are the thermal resistance or thermal transmittance of buildings' components [3]. Considering one-dimensional steady-state thermal conduction of a constructive component of the building (such as roofs or walls), these parameters represent the heat transfer taking place through the referred constructive component [4]. Nonetheless, many parameters can be analysed, and several options of intervention can be used to achieve better EE levels in buildings. Different multi-criteria 
decision-making processes are available to support such a choice, and an extensive review of them can be found in $[5,6]$.

One of the widely used is the Analytic Hierarchy Process (AHP) developed by Saaty [7]. It is a subjective method for analysing qualitative criteria where all parameters or criteria are allocated with a weight indicating the importance of each criterion. A hierarchical structure is used to model the decision-making process. For each hierarchical level, the decision-maker must make a pairwise comparison between the alternatives and the criteria, employing a scaling ratio for the weighing of attributes. The method determines the priorities of the decision alternatives, making possible to create a ranking, as well as allowing the verification of the internal consistency of the weighting assigned to each criterion [8]. Thus, the AHP method provides, as a result, a plan of preference and alternatives based on the level of importance given to the different criteria [9]. Several scientific investigations were developed using the AHP method for the relevance evaluation of different refurbishment buildings options [10-14], as well as to compare and choose the best energy efficiency policies at national level according to each economic sector [15-18]. Further details regarding the AHP method can be found in $[19,20]$.

As previously referred, several options of intervention are available to increase buildings thermal performance, and the choice must be made considering the efficiency of the solution and the possible costs involved. Considering this, this paper aims to develop a parametric study of several energy retrofit solutions for a building located in the hot-humid climate of Asunción, Paraguay, in order to analyse their efficiency in terms of comfort rates and cooling energy needs. Furthermore, the AHP is employed as the decision-making method to choose the most appropriate intervention considering the investment costs required. The general objective of this research work is to establish threshold values of thermal transmittance for building thermal envelope components, in order to contribute to the regulation of thermal parameters to improve the EE of Paraguayan buildings.

\section{Methodology}

This research has mainly seven steps briefly described below and summarised in Figure 1:

(a) Taking as a base the original state of the building, and holding constant orientation, window size, window shading and input parameters for the simulations, different window glazing types, and different configurations for roofs and walls were evaluated;

(b) Considering the results in terms of comfort rates, cooling needs and the costs associated for each configuration evaluated in (a), the Analytic Hierarchy Process was applied to choose the best configuration for the roof, walls and glazing type;

(c) Once figured out the most recommended configuration for the building envelope components, the sensitivity of the building under different insulation thicknesses for roofs and walls analysing comfort rates and cooling needs was assessed;

(d) Considering the results in terms of comfort rates, cooling needs and the costs associated for each insulation thickness evaluated in (c), the Analytic Hierarchy Process was applied to choose the best insulation thickness for roof and walls;

(e) The building employing the best configurations of roofs, walls and glazing to evaluate the energy efficiency version was simulated;

(f) Taking as a base the energy efficiency version of the building used in (e), the building was rotated $180^{\circ}$ to evaluate its performance with a different orientation, holding constant the configurations of walls and roof.

(g) With the energy efficiency version of the building in the original orientation and rotated $180^{\circ}$, holding constant the glazing type and the walls and roofs configurations, and according to the orientation, using or not, window shading systems, different window-wall-ratio (WWR) were evaluated. 
A parametric study is developed in this research, in which dynamic energy simulations of a building performed using the EnergyPlus software and DesignBuilder interface. The weather data employed is the default one available in DesignBuilder for Asunción (Paraguay). The weather station corresponds to the Silvio Pettirossi airport, and the dataset cover a period of 18 years, from 1982 to 1999 for most stations. These hourly weather data are 'typical' data derived from hourly observations which correspond to a record of multiple years, where each selected month is representative of that month for the period of record [21]. The parameters used as evaluation indicators were operative temperature $\left(T_{o p}\right)$, which is employed to determine the discomfort rates, and the energy requirement of the thermal zone under analysis. The internal and external surface temperatures $\left(T_{s i}\right.$. and $T_{s e}$, respectively), and the heat transfer through the building's envelope are also studied.

The discomfort rate is computed considering two methods: the former, according to the acceptable indoor operative temperatures for buildings in the Category II of the standard EN 15251 for the design of buildings without mechanical cooling systems [22], which employs the adaptive method [23]; and the latter, applying the statistic method, using fixed threshold values of comfort temperature. This approach was already adopted for the thermal comfort assessment of buildings by several scientific research [24-29].

In order to set the fixed range for the city of Asunción, which does not have a national standard energy code, a scientific literature analysis was performed. The static models usually set fixed thresholds values of comfort temperatures, and they have been widely used in a significant number of thermal regulations around the world. In Portugal, the thermal regulation sets as acceptable temperatures the range between $18-25^{\circ} \mathrm{C}$ [30]. In Chile, the Sustainable Construction Code considers acceptable the temperatures between the range of $18-26^{\circ} \mathrm{C}$ [31]. In Brazil, the NBR 16401-2 [32] sets, as acceptable temperatures, the range between $23-26^{\circ} \mathrm{C}$ in the summer season with a relative humidity of $35 \%$. The Chartered Institution of Building Services Engineers (CIBSE) [33] recommends a benchmark summer peak temperature of $28^{\circ} \mathrm{C}$ for dwelling's living areas.

In addition, several scientific research has been developed to set thresholds values of comfort temperature considering the climate under analysis. Lu et al. [34] developed a field study of thermal comfort in a building without cooling systems located the tropical island climate of China; the results suggest an admissible comfort temperature range for the residents from $23.1^{\circ} \mathrm{C}$ to $29.1{ }^{\circ} \mathrm{C}$. Djamila et al. [35] explored the thermal perceptions of people in the humid tropics of Malaysia employing different thermal perception approach; the results suggest that the optimum temperature was found to be about $30^{\circ} \mathrm{C}$.

The research developed by Lopez et al. [36] may be the sole work assessing thermal comfort conditions taking as case study Paraguay. For the referred work, three naturally-ventilated buildings in Asunción were evaluated, and the results were compared to three different methodologies. The outcomes of the research proven that heat discomfort was overestimated by the standard ISO 7730 when air temperature values exceeded $30^{\circ} \mathrm{C}$ since users reported neutral thermal conditions, while the method indicated intense heat discomfort. Furthermore, it was stated that methods employing equations as a function of the outdoor climate variables could successfully adjust to the hot-humid climatic context. In this way, it is possible to assert that the occupants of naturally-ventilated buildings have a higher tolerance of high temperatures and greater thermal comfort range. Considering the fixed ranges employed by the reviewed standards and those obtained from scientific researches, the fixed range used for this research was $18^{\circ} \mathrm{C}$ to $27^{\circ} \mathrm{C}$.

Thus, annually, weekly and daily indoor air temperature profiles are modelled hourly for the thermal zone presenting the worse thermal performance and, the percentage of the simulated time in which the operative temperatures exceed $27^{\circ} \mathrm{C}$ or the value recommended by the EN 15251 for buildings in the Category II, corresponds to the overheating rate. Similarly, the percentage of the simulated time in which the operative temperatures are lower than $18^{\circ} \mathrm{C}$ or the value recommended by the EN 15251 for buildings in the Category II, corresponds to the underheating rate. In addition, other simulations were run to analyse the building profiles of cooling energy needs. These analyses 
aim to calculate the amount of sensible energy that must be removed during the summer season, in order to ensure comfortable indoor conditions.

In this way, simulations during the whole year to determine the comfort rates and energy requirement were performed. The hottest and coldest week of the year with hourly intervals were also considered to analyse the results regarding heat transfer through building envelope components. Furthermore, the hottest day of a year was simulated to analyse the results in terms of surface temperatures and to calculate the time shift value of the configurations under analysis.

Regarding the methodology for the decision-making process [9], the first step involves building the hierarchy model, which has mainly three hierarchical levels: the main objective on the top, the criteria on the following level and the alternatives in the last level. For this work, the main objective is to choose, firstly, the best configuration for glazing areas, roofs and walls, and subsequently, to choose the most recommended insulation thickness for roofs and walls.

For the second level, three common criteria were set for assessing the priorities in glazing, roof and walls interventions, and one additional criterion was added for the evaluation of the walls. The criteria are the annual comfort rate, which represents the percentage of the time the thermal zone is within the comfort range set for the static approach. Then, considering that a hot-humid climate is analysed for this work, where the major discomfort rates are due to overheating conditions, the cooling needs were also considered as a criterion for the decision-making process. The cooling needs are represented by the overall sensible cooling effect on the zone of any air entered in the zone through the cooling system, in other words, it is the total cooling contribution to the heat balance of the thermal zone under analysis [21]. The costs involved with the intervention, which include the costs for labour and materials taking as a base the original state of the building, and for the Paraguayan construction market were also considered. Finally, for the walls was also considered the wall thicknesses, in order to considerer the efficiency of walls with lower thickness allowing a greater indoor useful area of the thermal zone under analysis. Regarding the alternatives, six options were considered for the glazing, four for the roof, and nine for the walls.

The second step involves the establishment of priorities for the criteria, the weights. For this purpose, the criteria are compared pairwise concerning the wanted goal to derive their weights. The values depicted in Table 1 are used to set the weights. The third step involves the establishment of local priorities (weights) for the alternatives, comparing the alternatives pairwise regarding every criterion, for which the scale of values is in Table 1. For these two steps previously referred, a review of the allocated weights values has to be done to check consistency regarding proportionality and transitivity [9]. The consistency ratio (CR) shall be between 0 and 0.1 to proceed with the AHP analysis. If it is higher than 0.10 , a revision of the weight allocated is necessary to find the reason of the inconsistency in order to put it right.

Table 1. The AHP pairwise comparison scale [7].

\begin{tabular}{cc}
$\begin{array}{c}\text { Intensity of Importance on an } \\
\text { Absolute Scale }\end{array}$ & Definition \\
\hline 1 & The two criteria/alternatives are equally important and contribute equally \\
to the objective
\end{tabular}

Finally, in the last step, the global priority vector is obtained. For this purpose, the alternatives priorities must be combined through a weighted sum in order to establish the overall priorities of the alternatives. Thus, the alternative with the highest overall priority is the most recommended choice [9]. The global priority vector is calculated through the elaboration of an overall matrix that includes the 
local priorities of each alternative concerning each criterion. Then, each column of vectors is multiplied by the priority corresponding to each criterion and added to each row, which results in the desired vector of best alternatives ordered in a ranking of importance or preference [7]. Further information about the methodology, the formulas used in the method, the theorems and considerations can be found in [7].

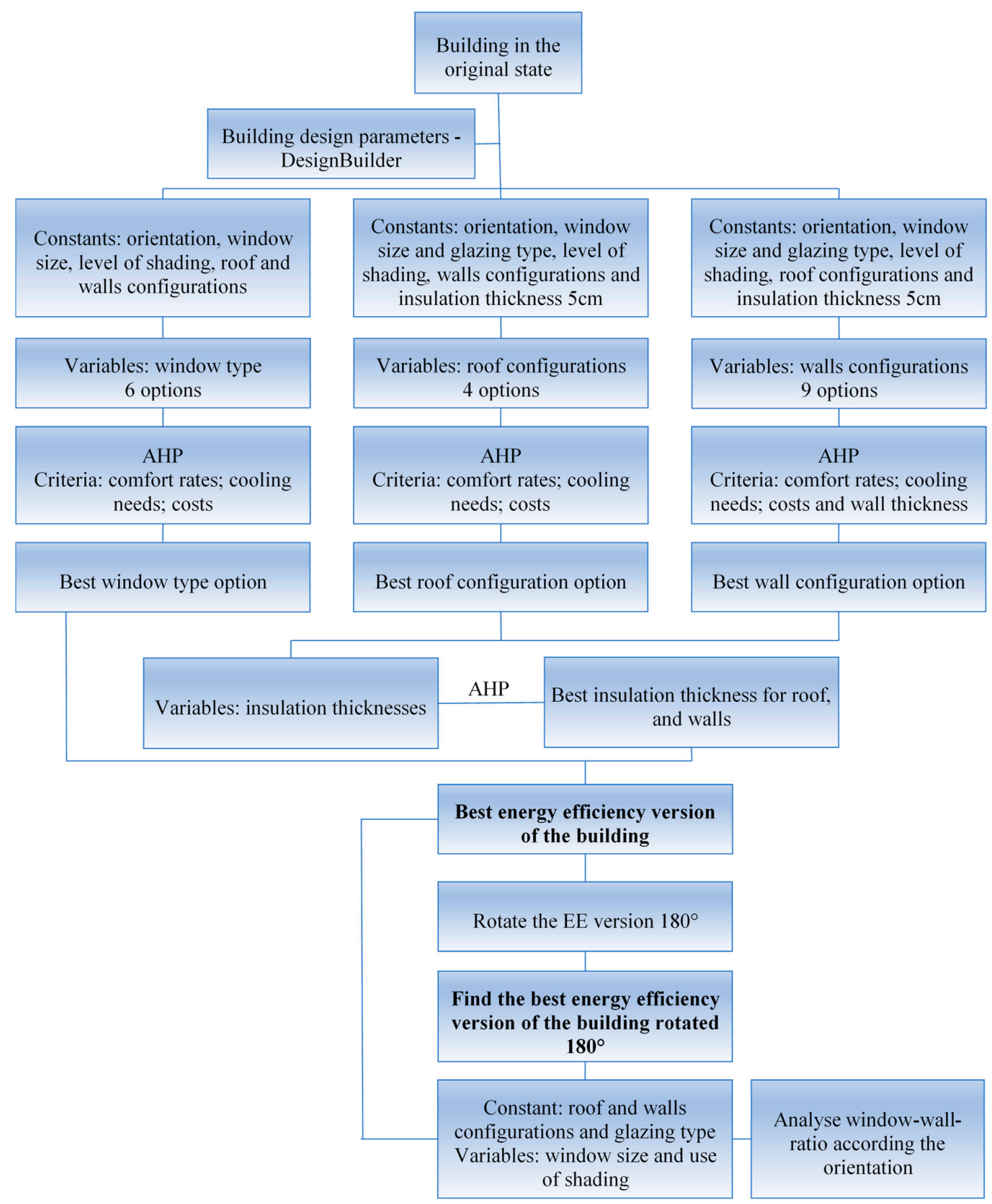

Figure 1. Methodology of the work.

\section{Case Study Characterisation}

The building taken as case study consists of a single two-storey family dwelling. The ground floor is composed of four thermal zones (lounge, circulations, bathroom, dining room and a kitchen) and the first floor has three thermal zones (two bedrooms and one lounge) (see Figure 2). The main thermal 
zone under analysis and for which the results are depicted corresponds to the Bedroom 2, a thermal zone on the first floor and with an east orientation, which in the original state has two walls surfaces interacting with the outdoor conditions, the main facade with northwest (NW) orientation and the lateral southwest (SW) facade. The zone has been chosen because, considering its exposition and orientation, it records the worst comfort conditions and the highest energy demand. In the following subsection are described the thermal properties of the building's envelope components evaluated in this research (Tables 3 and 4). The metabolic factor used for all thermal zones was equal to 1 , while the values for clothing insulation were 0.5 clo and 1 clo for the summer and winter season, respectively. Table 2 depicts the input parameters used for the dynamic simulations according to every thermal zone of the building.

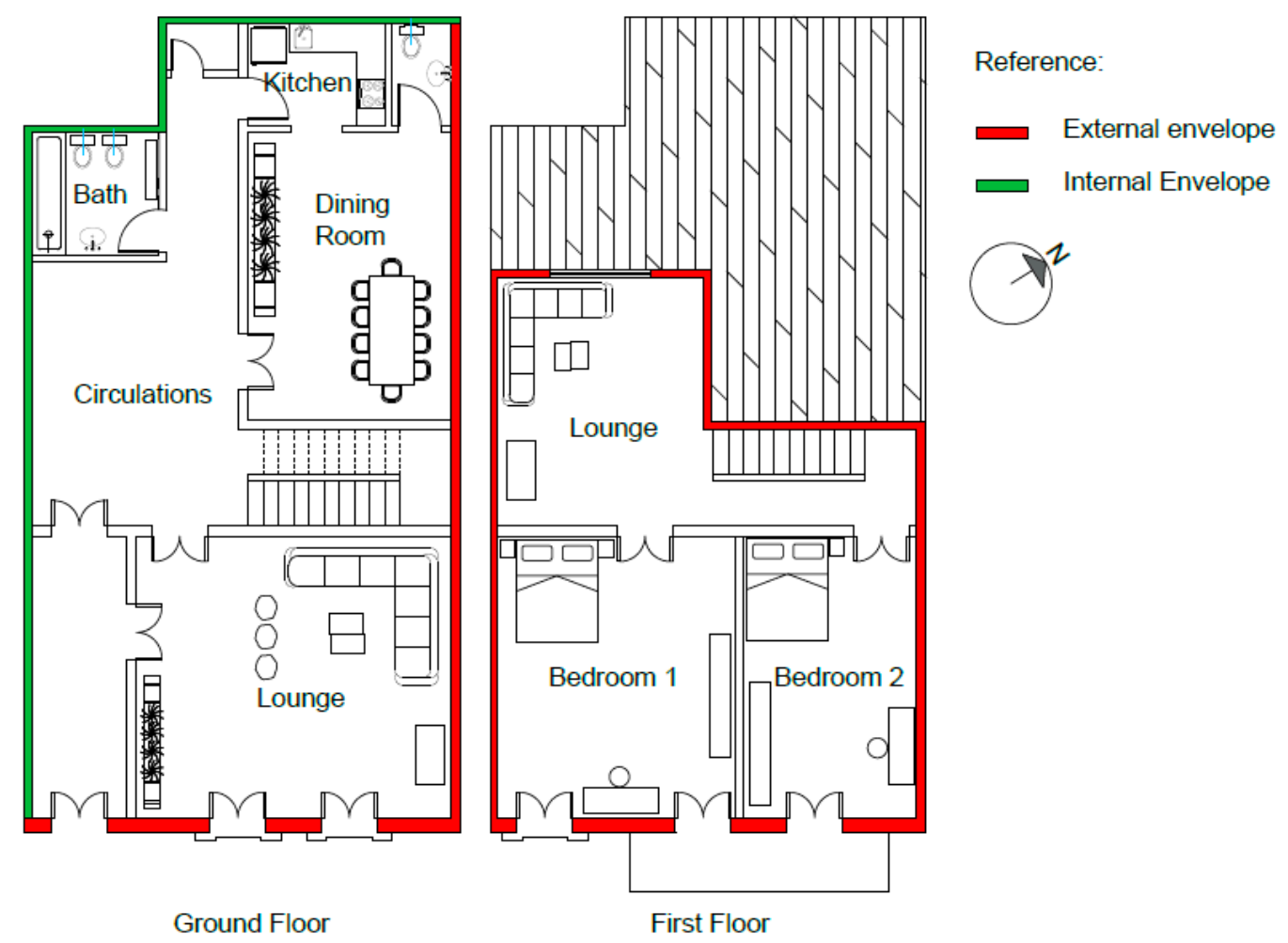

Figure 2. Architectural blueprints and thermal envelope characterisation of the case study.

For the thermal comfort evaluation, any heating or cooling system is considered. Nevertheless, natural ventilation is taken into account, where the natural ventilation rate was established in 5 air changes per hour. Natural ventilation is allowed according to the windows operation schedule. Hence, in the warmer seasons windows are open allowing natural ventilation only when the outdoor temperature is lower than indoor temperature. However, natural ventilation is restricted when the outside temperature is lower than $20^{\circ} \mathrm{C}$. For the winter season, windows are open only when the operative temperature is higher than the comfort temperature calculated from the CEN 15251 adaptive comfort model [22], considering that some days in winter season can reach high values of temperature.

Regarding the window shading (exterior Venetian blinds), the schedule of aperture operation for winter season is: 100\% open from 8 am to $6 \mathrm{pm}$ and fully closed the rest of the day. For the summer season, the shading is active when the solar radiation on the window reaches the medium solar setpoint of $189 \mathrm{~W} / \mathrm{m}^{2}$ [37], with the objective of reducing thermal discomfort because of direct solar radiation but taking advantage of natural daylight. 
Table 2. Input parameters set for the simulations. The occupation density ( $\mathrm{m}^{2} /$ person), the minimum fresh air (l/s-person), the target illuminance (Lux), the internal gains $\left(\mathrm{W} / \mathrm{m}^{2}\right)$ and the occupation schedules are shown.

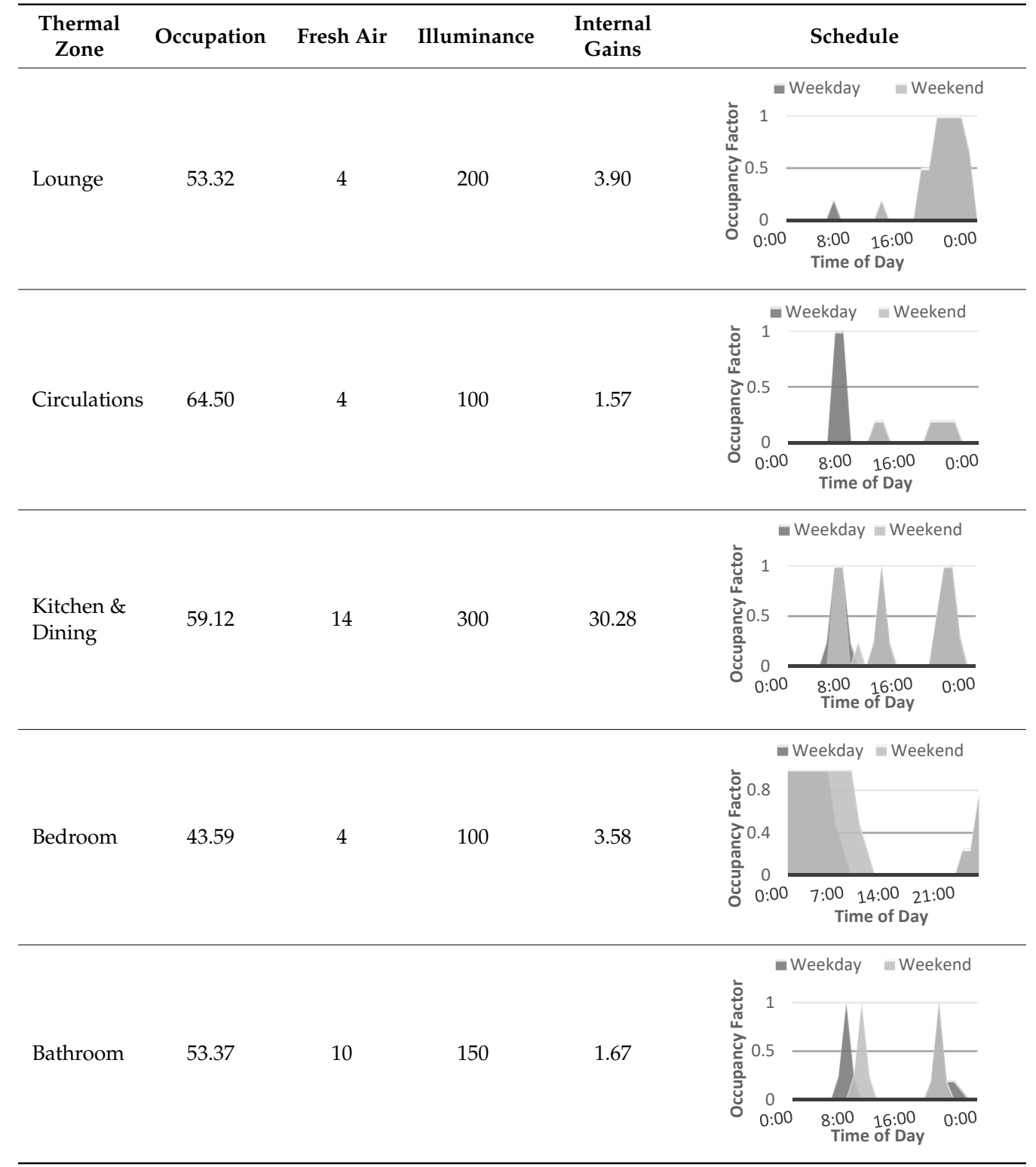

\section{Energy Retrofit Solutions Configuration}

At this stage of defining the energy rehabilitation strategies, several possibilities of intervention have been analysed, considering the most commonly used configurations in the country. The constructive solutions and their thermal parameters are described in Table 3 for the glazing and Table 4 for roofs and walls.

For calculating the thermal parameters of the roofs R3 and R4, an equivalent constant thickness was used for the air gap. In addition, for some constructive components was considered their thermal resistance $\left(R_{t}\right)$ instead of their thermal conductivity. Six different options were evaluated for the glazing, four for the roofs and nine for the walls. 
Table 3. Description of glazing type considered. For each layer, the values of $\mathbf{s}$ (thickness), $\boldsymbol{\lambda}$ (thermal conductivity), $\mathbf{U}$ (thermal transmittance), e (emissivity), and ST (solar transmittance) are shown.

\begin{tabular}{|c|c|c|c|c|c|c|}
\hline $\begin{array}{l}\text { Building } \\
\text { Component }\end{array}$ & Material (Outer to Inner) & $s(\mathrm{~m})$ & $\lambda(\mathrm{W} / \mathrm{m} \mathrm{K})$ & $e(-)$ & $S T(-)$ & $U\left(\mathrm{~W} / \mathrm{m}^{2} \mathrm{~K}\right)$ \\
\hline G-Glazing & $\begin{array}{l}\text { G1 - (a) Single Clear glazing } \\
\text { G2 - (a) Reflectance glazing } \\
\text { G3 - (a) Low-e glazing } \\
\text { G6 - (a) Reflectance glazing }\end{array}$ & $\begin{array}{l}0.006 \\
0.006 \\
0.006 \\
0.010\end{array}$ & $\begin{array}{l}0.90 \\
0.90 \\
0.90 \\
0.90\end{array}$ & $\begin{array}{l}0.84 \\
0.84 \\
0.20 \\
0.84\end{array}$ & $\begin{array}{l}0.77 \\
0.48 \\
0.68 \\
0.33\end{array}$ & $\begin{array}{l}5.78 \\
5.78 \\
3.78 \\
5.63\end{array}$ \\
\hline $\begin{array}{l}\text { G4-Double } \\
\text { Glazing } \\
\text { outer (a)(b)(c) }\end{array}$ & $\begin{array}{l}\text { (a) Single clear glazing } \\
\text { (b) Air gap } \\
\text { (c) Single clear glazing }\end{array}$ & $\begin{array}{l}0.006 \\
0.010 \\
0.006\end{array}$ & $\begin{array}{c}0.90 \\
\boldsymbol{R}_{t}=0.15 \\
0.90\end{array}$ & $\begin{array}{l}0.84 \\
0.84\end{array}$ & $\begin{array}{l}0.77 \\
0.77\end{array}$ & 2.76 \\
\hline $\begin{array}{l}\text { G5-Double } \\
\text { Glazing } \\
\text { outer } \\
\text { (a)(b)(c) }\end{array}$ & $\begin{array}{l}\text { (a) Reflectance glazing } \\
\text { (b) Air gap } \\
\text { (c) Reflectance glazing }\end{array}$ & $\begin{array}{l}0.006 \\
0.010 \\
0.006\end{array}$ & $\begin{array}{c}0.90 \\
\boldsymbol{R}_{t}=0.15 \\
0.90\end{array}$ & $\begin{array}{l}0.84 \\
0.84\end{array}$ & $\begin{array}{l}0.48 \\
0.48\end{array}$ & 2.76 \\
\hline
\end{tabular}

Table 4. Building's envelope components description. The values of $\mathbf{s}$ (thickness), $\boldsymbol{\lambda}$ (thermal conductivity), $\mathrm{U}$ (thermal transmittance) and $M_{S}$ (thermal mass) are shown for each layer.

\begin{tabular}{|c|c|c|c|c|c|}
\hline Building Component & $\begin{array}{c}\text { Material } \\
\text { (Outer to Inner) }\end{array}$ & $\begin{array}{c}\mathrm{s} \\
(\mathrm{m})\end{array}$ & $\begin{array}{c}\lambda \\
(W / m K)\end{array}$ & $\begin{array}{c}U \\
\left(W / m^{2} K\right)\end{array}$ & $\begin{array}{c}M_{S} \\
\left(\mathbf{K g} / \mathbf{m}^{2}\right)\end{array}$ \\
\hline \multicolumn{6}{|c|}{ ROOF } \\
\hline R1 - Without insulation & $\begin{array}{l}\text { (a) High density wood } \\
\text { (b) Ceramic Clay Tile }\end{array}$ & $\begin{array}{l}0.025 \\
0.010\end{array}$ & $\begin{array}{l}0.29 \\
0.84\end{array}$ & 4.20 & 40 \\
\hline $\begin{array}{l}\text { R2 - Pitched Roof Tile } \\
\text { (a) } \\
\text { (c) }\end{array}$ & $\begin{array}{l}\text { (a) Ceramic clay tile } \\
\text { (b) Glass wool felt } \\
\text { (c) High density wood }\end{array}$ & $\begin{array}{l}0.010 \\
0.050 \\
0.025\end{array}$ & $\begin{array}{l}0.84 \\
0.04 \\
0.29\end{array}$ & 0.67 & 49 \\
\hline $\begin{array}{l}\text { R3 - Pitched Roof Tile } \\
\text { (a) } \\
\text { (b) } \\
\text { (c) } \\
\text { (e) }\end{array}$ & $\begin{array}{l}\text { (a) Ceramic clay tile } \\
\text { (b) High density wood } \\
\text { (c) Glass wool felt } \\
\text { (d) Air gap } \\
\text { (e) Plasterboard }\end{array}$ & $\begin{array}{l}0.010 \\
0.025 \\
0.050 \\
1.000 \\
0.030\end{array}$ & $\begin{array}{l}0.84 \\
0.29 \\
0.04 \\
0.25\end{array}$ & 0.57 & 1276 \\
\hline $\begin{array}{l}\text { R4 - Pitched Roof Tile } \\
\text { (a) } \\
\text { (b) } \\
\text { (c) } \\
\text { (d) }\end{array}$ & $\begin{array}{l}\text { (a) Ceramic clay tile } \\
\text { (b) High density wood } \\
\text { (c) Air gap } \\
\text { (d) Glass wool felt } \\
\text { (e) Plasterboard }\end{array}$ & $\begin{array}{l}0.010 \\
0.025 \\
1.000 \\
0.050 \\
0.030\end{array}$ & $\begin{array}{l}0.84 \\
0.29 \\
0.04 \\
0.25\end{array}$ & 0.57 & 1276 \\
\hline \multicolumn{6}{|c|}{ WALLS } \\
\hline \multicolumn{6}{|c|}{ W1: Without insulation (original state) } \\
\hline $\begin{array}{l}\text { W1a - SW orientation } \\
20 \mathrm{~cm} \text { Wall }\end{array}$ & $\begin{array}{l}\text { (a) Sand lime plaster } \\
\text { (b) Solid Brick Burned } \\
\text { (c) Sand-lime plaster }\end{array}$ & $\begin{array}{l}0.015 \\
0.170 \\
0.015\end{array}$ & $\begin{array}{l}1.15 \\
0.85 \\
1.15\end{array}$ & 2.53 & 309 \\
\hline $\begin{array}{l}\text { W1b - NW orientation } \\
30 \mathrm{~cm} \text { Wall }\end{array}$ & $\begin{array}{l}\text { (a) Sand lime plaster } \\
\text { (b) Solid Brick Burned } \\
\text { (c) Sand lime plaster }\end{array}$ & $\begin{array}{l}0.015 \\
0.270 \\
0.015\end{array}$ & $\begin{array}{l}1.15 \\
0.85 \\
1.15\end{array}$ & 1.95 & 459 \\
\hline
\end{tabular}


Table 4. Cont.

\begin{tabular}{|c|c|c|c|c|c|}
\hline Building Component & $\begin{array}{c}\text { Material } \\
\text { (Outer to Inner) }\end{array}$ & $\begin{array}{l}\mathrm{s} \\
(\mathrm{m})\end{array}$ & $\begin{array}{c}\lambda \\
(W / m K)\end{array}$ & $\begin{array}{c}\mathrm{U} \\
\left(\mathrm{W} / \mathrm{m}^{2} \mathrm{~K}\right)\end{array}$ & $\begin{array}{c}M_{s} \\
\left(\mathrm{Kg} / \mathrm{m}^{2}\right)\end{array}$ \\
\hline \multicolumn{6}{|c|}{ External (W2) and internal (W3) cladding with insulation } \\
\hline W2a - SW orientation & (a) Sand cement plaster & 0.010 & 0.42 & \multirow{5}{*}{0.60} & \multirow{5}{*}{348} \\
\hline $26 \mathrm{~cm}$ Wall & (b) Glass wool felt & 0.050 & 0.04 & & \\
\hline Fin & (c) Sand-lime plaster & 0.015 & 1.15 & & \\
\hline \multirow{2}{*}{$\begin{array}{l}\text { outer } 1 \text { inner } \\
\text { (a) (b) (c) (d) (e) }\end{array}$} & (d) Solid brick burned & 0.170 & 0.85 & & \\
\hline & (e) Sand-lime plaster & 0.015 & 1.15 & & \\
\hline W2b- NW orientation & (a) Sand cement plaster & 0.010 & 0.42 & \multirow{5}{*}{0.56} & \multirow{5}{*}{498} \\
\hline $36 \mathrm{~cm}$ Wall & (b) Glass wool felt & 0.050 & 0.04 & & \\
\hline 盗 & (c) Sand lime plaster & 0.015 & 1.15 & & \\
\hline outer inner & (d) Solid brick burned & 0.270 & 0.85 & & \\
\hline$(a)(b)(c)(d)(e)$ & (e) Sand lime plaster & 0.015 & 1.15 & & \\
\hline \multicolumn{6}{|c|}{ Inner (W4) and exterior (W6) cladding with hollow brick leaving an air gap } \\
\hline W4a - SW orientation & (a) Sand lime plaster & 0.015 & 1.15 & \multirow{6}{*}{1.04} & \multirow{6}{*}{505} \\
\hline $31.5 \mathrm{~cm}$ Wall & (b) Solid brick burned & 0.170 & 0.85 & & \\
\hline 田围 & (c) Sand lime plaster & 0.015 & 1.15 & & \\
\hline 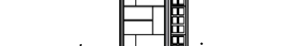 & (d) Air gap & 0.025 & $\boldsymbol{R}_{t}=0.19$ & & \\
\hline outer & (e) Hollow brick & 0.050 & $\boldsymbol{R}_{t}=0.35$ & & \\
\hline & (f) Sand cement plaster & 0.010 & 0.42 & & \\
\hline W4b - NW orientation & (a) Sand lime plaster & 0.015 & 1.15 & \multirow{6}{*}{0.93} & \multirow{6}{*}{655} \\
\hline $41.5 \mathrm{~cm}$ Wall & (b) Solid brick burned & 0.270 & 0.85 & & \\
\hline \multirow{4}{*}{ 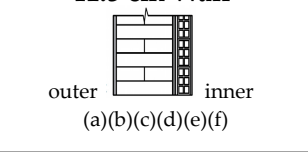 } & (c) Sand lime plaster & 0.015 & 1.15 & & \\
\hline & (d) Air gap & 0.025 & $\boldsymbol{R}_{t}=0.19$ & & \\
\hline & (e) Hollow brick & 0.050 & $\boldsymbol{R}_{t}=0.35$ & & \\
\hline & (f) Sand cement plaster & 0.010 & 0.42 & & \\
\hline \multicolumn{6}{|c|}{ Inner (W5) and exterior (W7) cladding with insulation and hollow brick } \\
\hline W5a - SW orientation & (a) Sand lime plaster & 0.015 & 1.15 & \multirow{6}{*}{0.49} & \multirow{6}{*}{484} \\
\hline $34 \mathrm{~cm}$ Wall & (b) Solid brick burned & 0.170 & 0.85 & & \\
\hline & (c) Sand lime plaster & 0.015 & 1.15 & & \\
\hline & (d) Glass wool felt & 0.050 & 0.04 & & \\
\hline outer Tr & (e) Hollow brick & 0.080 & $\boldsymbol{R}_{t}=0.35$ & & \\
\hline (b)(c)(d)(e)(f) & (f) Sand cement plaster & 0.010 & 0.42 & & \\
\hline \multirow{6}{*}{$\begin{array}{l}\text { W5b - NW orientation } \\
\begin{array}{c}\text { outer } \\
\text { (a)(b)(c)(d)(e)(f) }\end{array}\end{array}$} & (a) Sand lime plaster & 0.015 & 1.15 & \multirow{6}{*}{0.47} & \multirow{6}{*}{634} \\
\hline & (b) Solid brick burned & 0.270 & 0.85 & & \\
\hline & (c) Sand lime plaster & 0.015 & 1.15 & & \\
\hline & (d) Glass wool felt & 0.050 & 0.04 & & \\
\hline & (e) Hollow brick & 0.080 & $\boldsymbol{R}_{t}=0.35$ & & \\
\hline & (f) Sand cement plaster & 0.010 & 0.42 & & \\
\hline \multicolumn{6}{|c|}{ Inner (W8) and exterior (W9) cladding with insulation and solid brick } \\
\hline \multirow{6}{*}{$\begin{array}{l}\text { W8a - SW orientation } \\
31 \mathrm{~cm} \text { Wall } \\
\text { outer (b)(c)(d)(e)(f) }\end{array}$} & (a) Sand lime plaster & 0.015 & 1.15 & \multirow{6}{*}{0.58} & \\
\hline & (b) Solid brick burned & 0.170 & 0.85 & & \\
\hline & (c) Sand lime plaster & 0.015 & 1.15 & & \\
\hline & (d) Glass wool felt & 0.080 & 0.04 & & 433 \\
\hline & (e) Solid brick burned & 0.050 & 0.85 & & \\
\hline & (f) Sand cement plaster & 0.015 & 0.35 & & \\
\hline W8b - NW orientation & (a) Sand lime plaster & 0.015 & 1.15 & & \\
\hline $41 \mathrm{~cm}$ Wall & (b) Solid brick burned & 0.270 & 0.85 & & \\
\hline F阙 & (c) Sand lime plaster & 0.015 & 1.15 & 054 & 583 \\
\hline 12 & (d) Glass wool felt & 0.080 & 0.04 & 0.54 & 583 \\
\hline outer 专 inner & (e) Solid brick burned & 0.050 & 0.85 & & \\
\hline (a)(b)(c)(d)(e)(f) & (f) Sand cement plaster & 0.015 & 0.35 & & \\
\hline
\end{tabular}

\section{Results and Discussion}

Once the building component configurations were defined, coupled with the constants and variants to consider, the dynamic energy simulations were carried out, and the results are summarised in this section. 


\subsection{Configurations for Glazing Type}

The first action involved the change of the glazing type, for which six options were considered. For analysing the influence of the shading system, one simulation was run without considering it. The results regarding comfort rates are in Figure 3, where no significant differences can be observed among the results according to the glazing types employed for both, the static approach and the adaptive method. This can be attributed to the fact that the glazing areas in the thermal zone under analysis are not too large, being the WWR equal to $8.7 \%$, a value lower than $10 \%$ as recommended by Alwetaishi [38] for buildings in hot-humid climates.

(a) Fixed Range

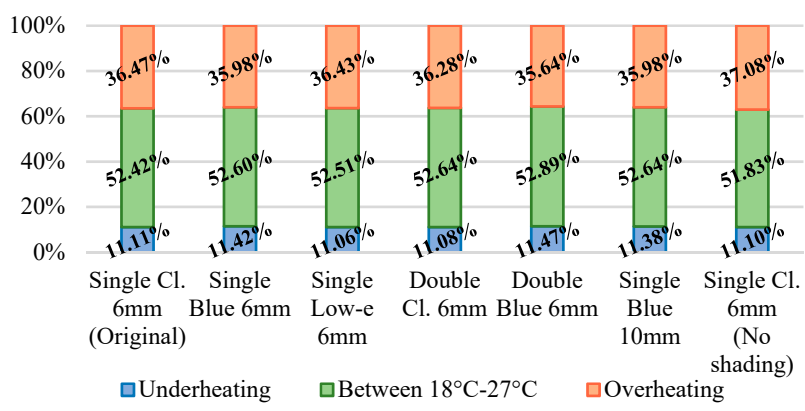

(b) Category II - EN15251

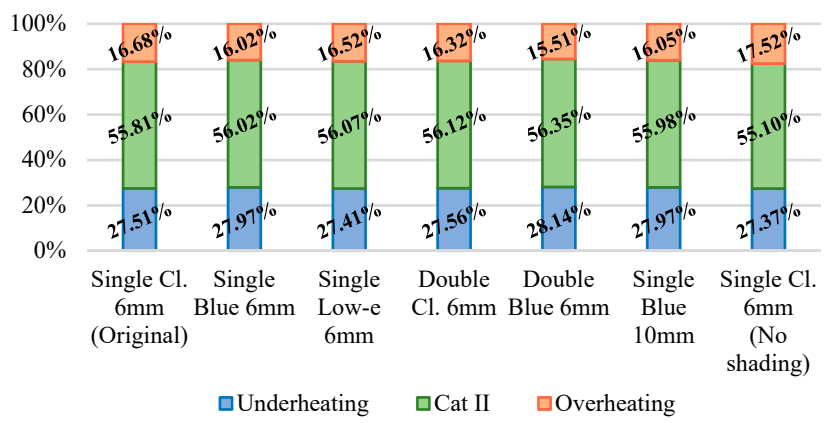

Figure 3. Comfort rates according to the fixed range (a) and the EN15251 for Category II (b) considering different glazing types.

As depicted in Figure 4a, the same trend is detected analysing the annual energy requirements, that does not change significantly according to the glazing type employed, for both cooling and heating needs. Figure $4 \mathrm{~b}$ shows the solar gains to the zone through the glazing areas during the hottest and coldest week of a year, where can be seen how the use of shading systems collaborate to minimise the solar gains during the summer period. Furthermore, considering that the major discomfort rates in the zone correspond to the overheating one, the blue reflective glazing type delivered the best results since the lowest solar gains during the hottest week were delivered with the simulations employing this glazing type.

\subsection{Configurations for the Roof}

Subsequently, the simulations for the four configurations of the roof were performed, and the results regarding comfort rates and energy requirement are depicted in Figures 5 and 6a, respectively. Analysing the results of comfort rates, it is observed that the option 3 and option 4 delivered the highest percentage within the comfort range, presenting the option 4 the lowest overheating rates, for both the static and adaptive approach. Also, it can be observed that only improving the roof insulation, the annual discomfort rates can decrease by $7.4 \%$ for the static approach and $13.3 \%$ considering the adaptive method. The same trend is performed for the annual energy requirement analysis since the 
lowest cooling and heating needs are delivered by R3 and R4, for which the annual energy requirement can decrease around $37 \%$ regarding the original state of the building.

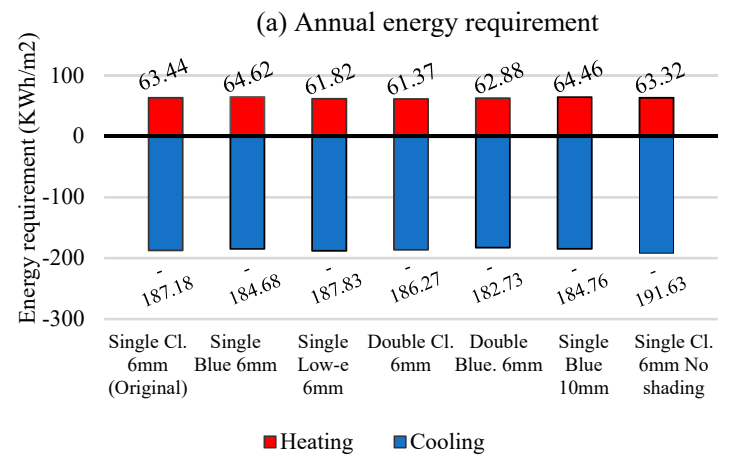

(b) Solar gains through glazing areas

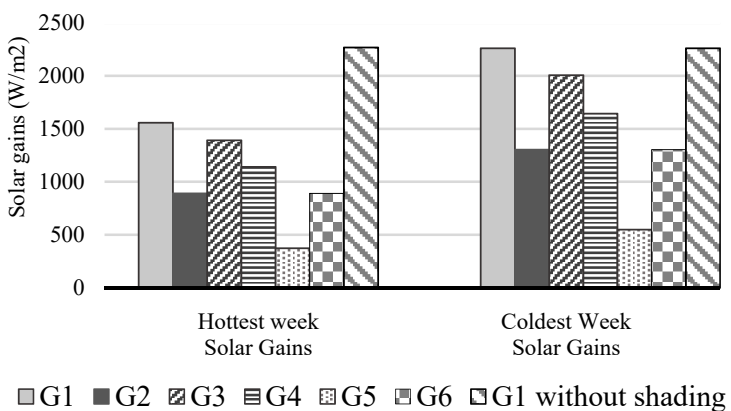

Figure 4. Annual Energy requirement (a) and solar gains (b) considering different glazing types.

(a) Fixed Range

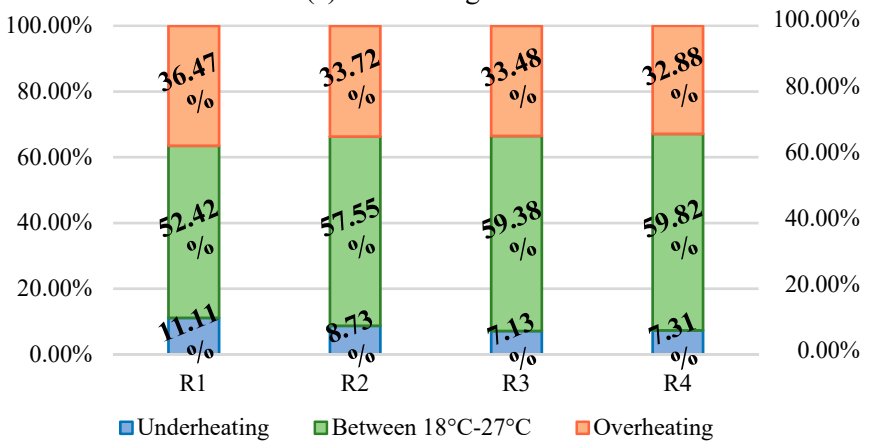

(b) Category II - EN15251

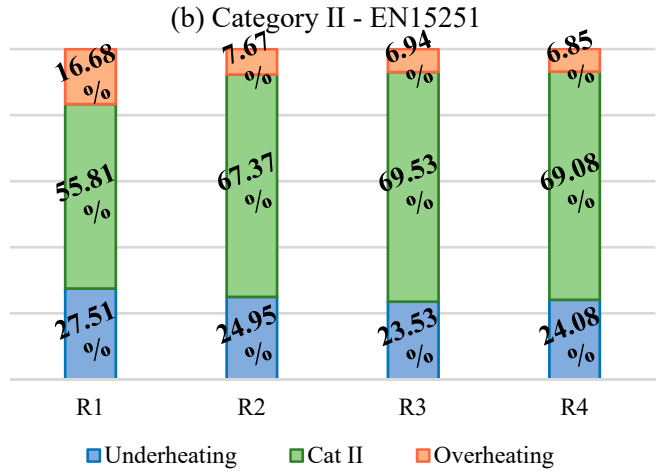

Figure 5. Comfort rates according to the fixed range (a) and the EN15251 for Category II (b) for different roof configurations.

(a) Annual energy requirement

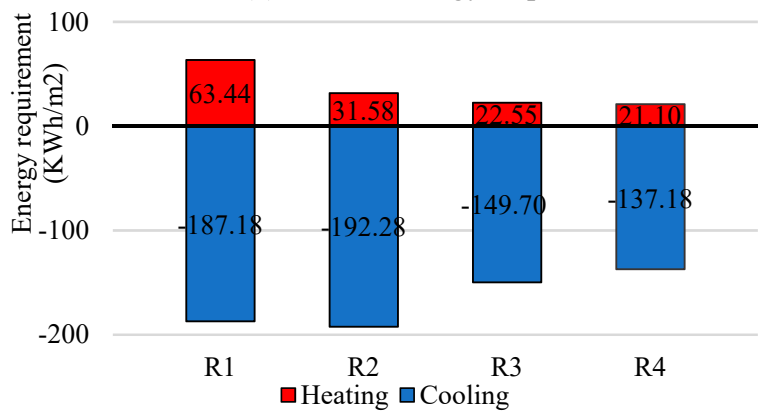

(b) Heat gains to the zone from the roof

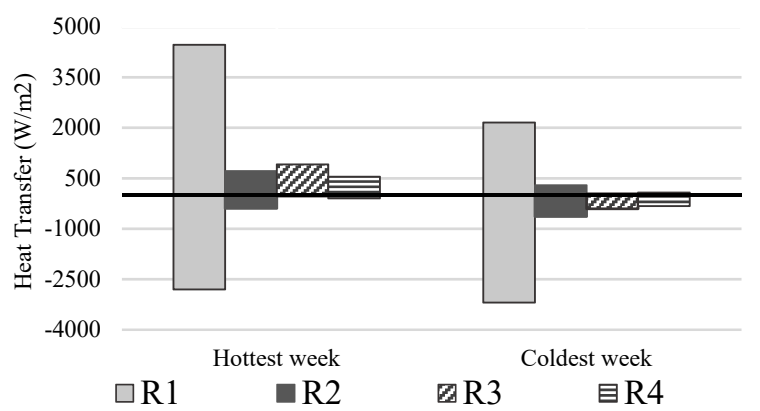

Figure 6. Annual Energy requirement (a) and heat gains (b) for different roof configurations.

Figure $6 \mathrm{~b}$ depicts the heat transfer through the roof according to the configuration employed, where it can be seen how the roof of the original state of the building (R1) has the highest heat gains but also the highest heat losses. Furthermore, the heat transfer through the roof has significantly decreased considering the other three configurations used. The hottest day of a year was also simulated in order to analyse the surface temperatures of buildings envelope components, as depicted in Figure 7a, the maximum external and internal surface temperatures are recorded simultaneously, giving thus a time shift value equal to zero for the roof R1. Figure $7 \mathrm{~b}$ depicts that with the roof $\mathrm{R} 4$, this value increased to $5 \mathrm{~h}$, besides that the internal surface temperatures have significantly decreased, which has impacted the operative temperature, achieving lower indoor temperatures during the highest outdoor temperature conditions. Nonetheless, it is important to note that during the night, the 
outdoor temperatures are cooler than the interior ones, indicating the need to improve natural night ventilation rates.
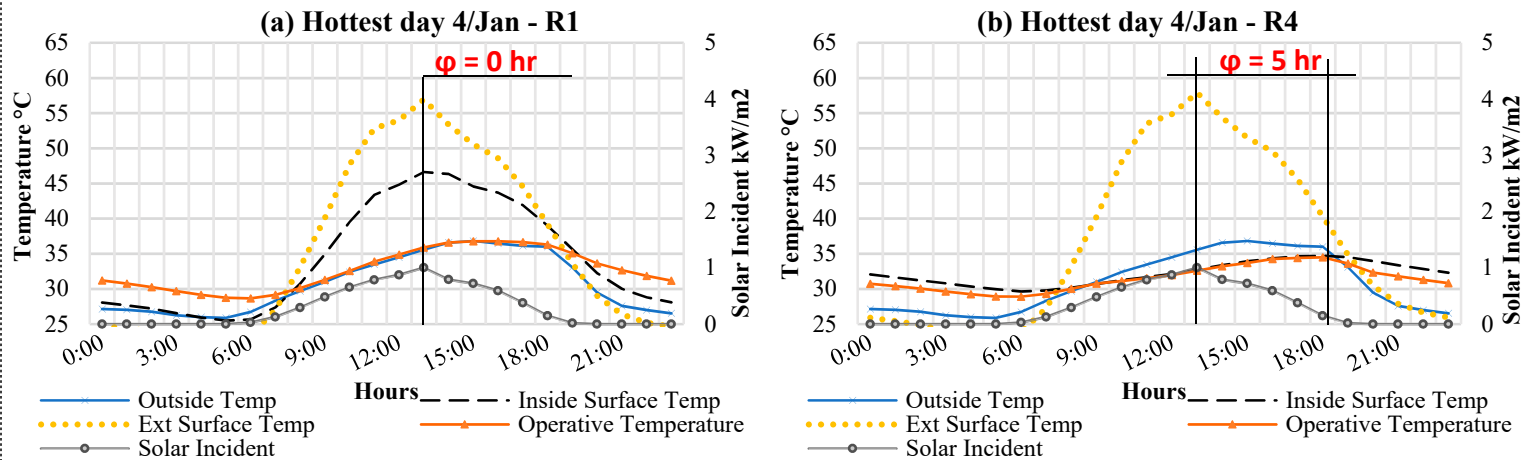

Figure 7. Surface temperatures for the roof in the original state R1 (a) and for the solution R4 (b).

\subsection{Configurations for the Walls}

The third step was to evaluate the nine configurations chosen for the walls taking as a base the original state of the building. Regarding comfort rates (Figure 8), the lowest underheating and overheating rates were recorded by the configurations employing exterior claddings (W2, W6, W7, W9); in fact, with an exterior reinforcement of exterior walls with $5 \mathrm{~cm}$ insulation (W2), it can be achieved an increase in the annual comfort rate of almost $7 \%$. Among the configurations using inner claddings (W3, W4, W5, W8), the W8 (inner reinforcement with insulation and solid brick) delivered the best results; nonetheless, no higher differences than $1.4 \%$ are recorded among them.
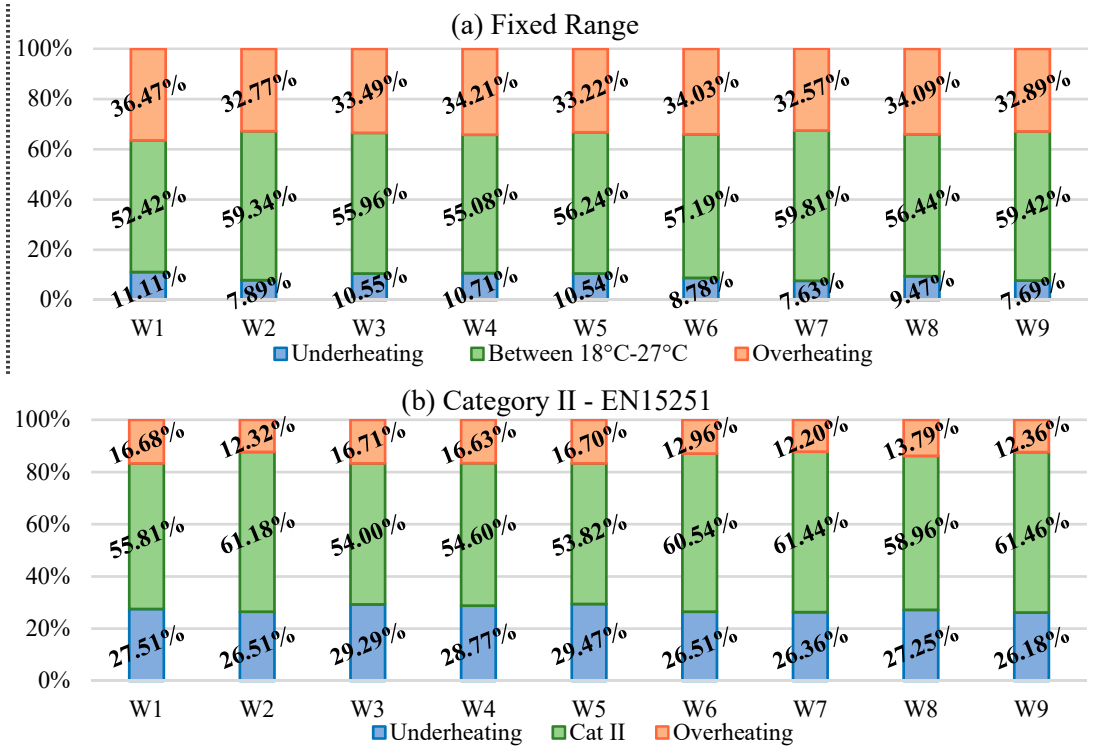

Figure 8. Comfort rates according to the static (a) and the adaptive (b) approach for different wall configurations.

Regarding cooling and heating needs, Figure 9a depicts the results according to the different walls configurations. It was detected that the changes in the total heat transfer of the walls (Figure 9b) influenced the annual energy requirements, also impacting in the heat transfer of the other envelope components of the building that were maintained in its original configuration. Thus, the walls which have lower heat transfer (W3 and W5), lead to the lowest cooling needs. For the heating needs, W2 delivered the lowest results. 
(a) Annual energy requirement

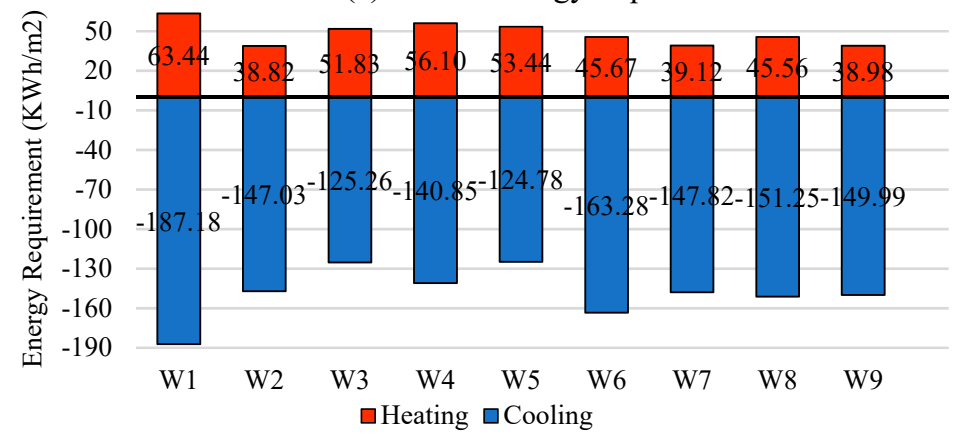

(b) Heat gains to the zone from the walls

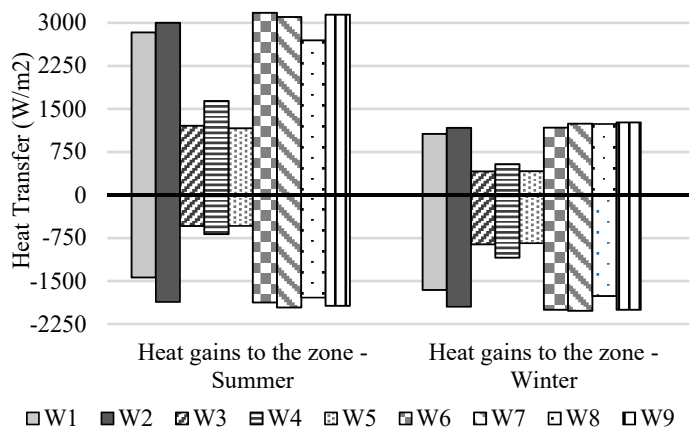

Figure 9. Annual Energy requirement (a) and heat gains (b) for different wall configurations.

Figures 10 and 11 depict the results regarding surface temperatures of the wall in the original state (a) and for the W2 configuration (b). For a southwest orientation (Figure 10), the external surface temperature is higher with the W2 than with the W1. Nonetheless, the internal one has significantly decreased with the wall W2, which also collaborated to slightly decrease the operative temperatures of the thermal zone. For a northwest orientation (Figure 11), the same performance is recorded, but the solar incident is higher, causing higher external surface temperatures. However, as W1 with $\mathrm{NW}$ orientation is $30 \mathrm{~cm}$-thick, the internal surface temperatures are lower, and with the addition of $5 \mathrm{~cm}$-thick insulation for the $\mathrm{W} 2$ configuration, the internal surface temperature becomes even lower also collaborating for the slightly lower operative temperatures of the zone. It is important to highlight that the time shift values referred in the graphs were calculated according to the results obtained from the simulations during the hottest day of a year, being thus the time difference between the maximum external surface temperature and the maximum internal one.
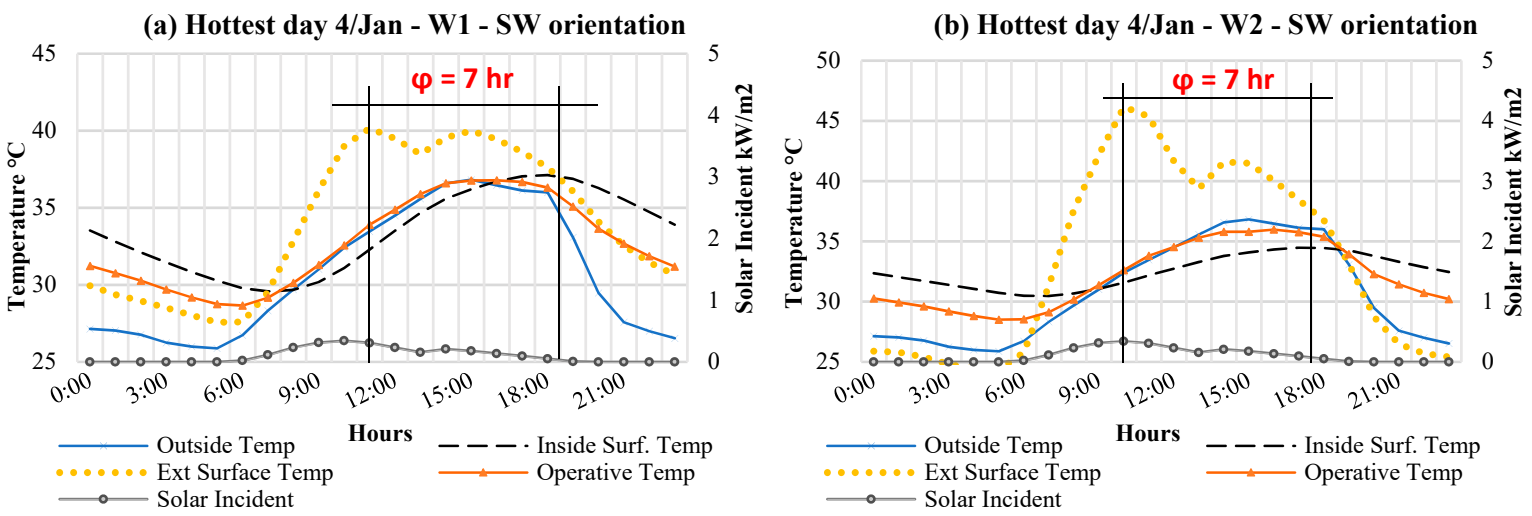

Figure 10. Surface temperatures for the wall with SW orientation in the original state W1 (a) and the solution W2 (b). 
(a) Hottest day 4/Jan - W1 - NW orientation

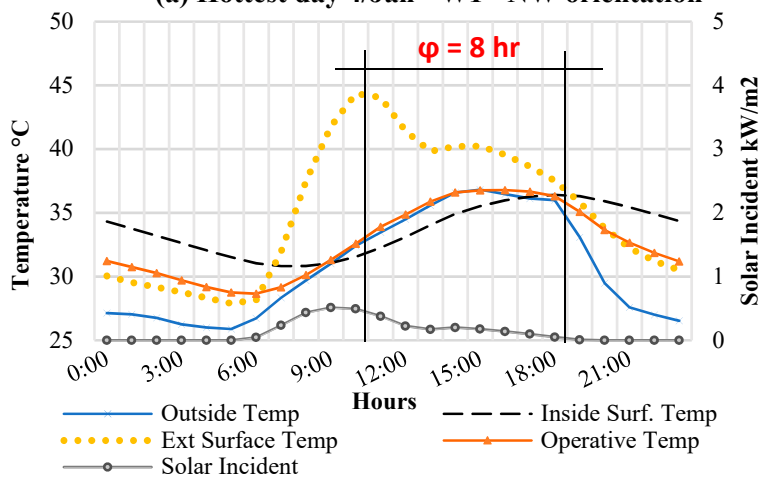

(b) Hottest day 4/Jan - W2 - NW orientation

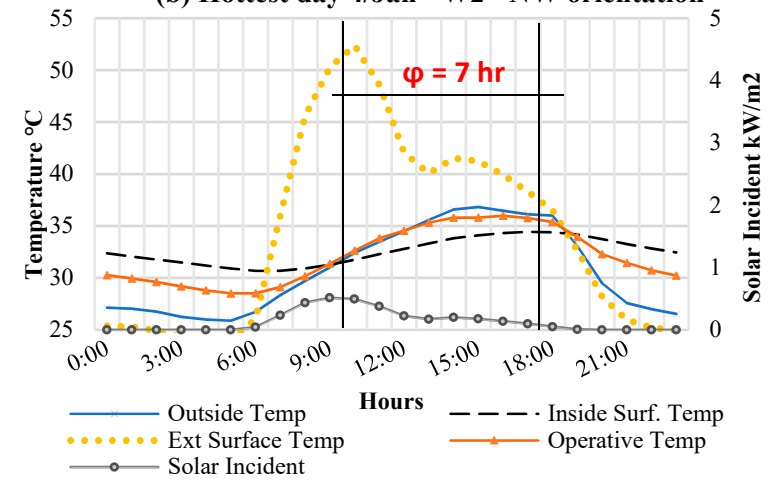

Figure 11. Surface temperatures for the wall with NW orientation in the original state W1 (a) and the solution W2 (b).

\subsection{Application of the AHP Method to Choose the Most Recommended Configuration}

Once all the configurations were evaluated, the AHP method was applied. For this purpose, the first step involves the establishment of the hierarchy structure. Regarding the criteria, the weights were allocated considering the results obtained from the simulations for comfort rates and cooling needs.

For the cost estimation, a market study of the Paraguayan construction industry was developed. The cost analysis considered to evaluate the proposed retrofit solutions was carried out through an analysis of reference costs. For the costs estimation, a market study of the Paraguayan construction industry was developed. The cost analysis considered to evaluate the proposed retrofit solutions was carried out through an analysis of reference costs. Thus, the monetary value of the retrofit solutions is not indicated, being used the percentage of cost increase associated with each solution referenced to the cost of the constructive component in its original state. Therefore, the costs of the G1, R1, W1, (glazing, roof and walls in the original state) have a value equal to 1 (reference cost), while the cost of each retrofit solution is indicated as a multiplier factor (value) in relation with the reference cost of each component.

For the glazing G1, for example, all the solutions involve an increase greater than 1 since a replacement of the original component is required implying a cost increase of $98 \%, 20 \%, 100 \%, 242 \%$ and 167\% for the retrofit solutions G2, G3, G4, G5 and G6, respectively. As G1 is a window with simple clear glazing of $6 \mathrm{~mm}$, and its reference cost is indicated as 1, G4 has a double price in the Paraguayan market, so, its cost related to the reference cost (G1) is 2.

In the case of the roof and walls, all the alternatives are associated with reference costs lower than 1 because the substitution of the original components is not necessary since the solution consists on the addition of insulating materials aiming to improve the thermal performance of the building envelope. Thus, the costs involved for each intervention are depicted in Table 5.

Table 5. Costs involved for each alternative under consideration.

\begin{tabular}{cccccc}
\hline Glazing & \multicolumn{3}{c}{ Roofs } & \multicolumn{3}{c}{ Walls } \\
\hline Alternative & Costs & Alternative & Costs & Alternative & Costs \\
\hline G1 & 1.00 & R1 & 1.00 & W1 & 1.00 \\
G2 & 1.98 & R2 & 0.32 & W2 & 0.31 \\
G3 & 1.20 & R3 & 0.38 & W3 & 0.31 \\
G4 & 2.00 & R4 & 0.38 & W4 & 0.54 \\
G5 & 3.42 & & & W5 & 0.64 \\
G6 & 2.67 & & & W6 & 0.54 \\
& & & & W7 & 0.64 \\
& & & & W9 & 0.61 \\
& & & & & 0.61 \\
\hline
\end{tabular}


Subsequently, the second step involves the set of priorities for the criteria, where the weights are assigned. For walls and roof, Tables 6 and 7 present the pairwise comparison matrix employed. For both, the highest priority is given to the comfort rates, considering that it considers the efficiency of the solutions for the warm and cold seasons. Then, as a mainly warm climate is under analysis, the cooling needs were considered as criteria and, it was considered as important as the comfort rates. In this way, the cost criteria were the least influential in the analysis when compared to the other referred criteria. Furthermore, for the walls, one additional criterion was taken into account, the walls thicknesses of the solution under analysis, which had the least influence when compared with the other criteria but, it was considered in order to give priority to the solutions allowing to preserve more indoor useful area. For glazing, considering that in terms of comfort rates and cooling needs the results did not vary significantly for the different configurations considered, it was decided to give a higher weight to the associated costs for each glazing type employed, considering that these costs are quite different between each other. For the same reason, the G1 was included as an alternative for the AHP analysis for the glazing, to analyse whether the intervention in glazing areas is justified. Thus, the pairwise comparison matrix for glazing is depicted in Table 8.

Table 6. Pairwise comparison matrix of criteria for roofs.

\begin{tabular}{lcccc}
\hline \multicolumn{5}{c}{ Roofs - Consistency Rate: $\mathbf{0 . 0 2 5}$} \\
\hline Criteria & Costs & Comfort Rate & Cooling Needs & Priority \\
\hline Costs & 1 & $1 / 5$ & $1 / 3$ & 0.11 \\
Comfort rate & 5 & 1 & 1 & 0.48 \\
Cooling & 3 & 1 & 1 & 0.41 \\
needs & & & & \\
\hline
\end{tabular}

Table 7. Pairwise comparison matrix of criteria for walls.

\begin{tabular}{lccccc}
\hline \multicolumn{1}{c}{ Walls - Consistency Rate: 0.027 } \\
\hline \multicolumn{1}{c}{ Criteria } & Costs & Comfort Rate & Cooling Needs & Wall Thickness & Priority \\
\hline Costs & 1 & $1 / 5$ & $1 / 2$ & 2 & 0.14 \\
Comfort rate & 5 & 1 & 2 & 4 & 0.51 \\
Cooling needs & 2 & $1 / 2$ & 1 & 3 & 0.26 \\
Wall thickness & $1 / 2$ & $1 / 4$ & $1 / 3$ & 1 & 0.09 \\
\hline
\end{tabular}

Table 8. Pairwise comparison matrix of criteria for glazing.

\begin{tabular}{lcccc}
\hline \multicolumn{5}{c}{ Glazing - Consistency Rate: $\mathbf{0 . 0 1 6}$} \\
\hline \multicolumn{1}{c}{ Criteria } & Costs & Comfort Rate & Cooling Needs & Priority \\
\hline Costs & 1 & 3 & 2 & 0.55 \\
Comfort rate & $1 / 3$ & 1 & 1 & 0.21 \\
Cooling needs & $1 / 2$ & 1 & 1 & 0.24 \\
\hline
\end{tabular}

The same procedure was employed to develop the pairwise comparison matrix among alternatives considering each criterion. Thus, the calculation of weight for each alternative and criterion was made, and the results from the combined synthesis model are illustrated in Table 9. Regarding the glazing, the results suggest that is not recommended to change the glazing type of the building since as was previously stated, no major differences are delivered by the simulations regarding comfort rates and cooling needs, however, the differences among the costs are meaningful. For the roofs, the analysis suggests that the best option is the configuration R4, followed by the R3 and finally the R2, even though the costs differences among the alternatives were not significant, the differences in terms of comfort rates and cooling needs influence the results. Regarding the walls, W2 and W3, employing 
exterior and inner insulation, respectively, delivered similar results, being the most recommended options for the walls, where the wall thickness made the difference to give priority to these options.

Table 9. Global priority vector for different configurations.

\begin{tabular}{ccccccccc}
\hline Glazing & \multicolumn{3}{c}{ Roofs } & \multicolumn{3}{c}{ Walls } \\
\hline Alternative & Weight & Rank & Alternative & Weight & Rank & Alternative & Weight & Rank \\
\hline G1 & 0.246 & 1 & R2 & 0.141 & 3 & W2 & 0.200 & 1 \\
G2 & 0.135 & 4 & R3 & 0.258 & 2 & W3 & 0.185 & 2 \\
G3 & 0.210 & 2 & R4 & 0.601 & 1 & W4 & 0.068 & 6 \\
G4 & 0.121 & 5 & & & & W5 & 0.124 & 5 \\
G5 & 0.186 & 3 & & & & W6 & 0.067 & 7 \\
G6 & 0.101 & 6 & & & & W7 & 0.162 & 3 \\
& & & & & & W9 & 0.055 & 8 \\
\end{tabular}

\subsection{Evaluation of Different Insulation Thicknesses for the Roof}

Once the most recommended configurations were set, the following step involves the use of each configuration for walls and roofs, but varying the insulation thickness, using as a base the original state of the building. Eight different insulation thicknesses were evaluated for the roof, employing the configuration R4. The thermal transmittance value of the roof with the different insulation thicknesses are shown in Table 10, and the results of the dynamic energy simulations are depicted in Figure 12. The first bar depicts the results of the original state of the building, which employs the configuration R1, the following bars depict the results employing the configuration R4 with the different insulation thicknesses. It can be seen that only with the division of the thermal zone with a horizontal plasterboard ceiling, creating an attic making the thermal zone not being in direct contact with the outdoor conditions through the roof, the results regarding comfort rates have significantly improved, even without the use of insulation materials.

Table 10. Thermal transmittance of roof $R 4$ according to the insulation thickness used.

\begin{tabular}{lc}
\hline \multicolumn{1}{c}{ Description } & $\mathrm{U}\left(\mathbf{W} / \mathrm{m}^{2} \mathbf{K}\right)$ \\
\hline $\mathrm{R} 1$ - Original state & 4.20 \\
\hline $\mathrm{R} 4$ - Without insulation & 1.97 \\
\hline $\mathrm{R} 4$ - Insulation $1 \mathrm{~cm}$ - thick & 1.32 \\
\hline $\mathrm{R} 4$ - Insulation $3 \mathrm{~cm}$ - thick & 0.79 \\
\hline $\mathrm{R} 4$ - Insulation $5 \mathrm{~cm}$ - thick & 0.57 \\
\hline $\mathrm{R} 4$ - Insulation $8 \mathrm{~cm}$ - thick & 0.34 \\
\hline $\mathrm{R} 4$ - Insulation $10 \mathrm{~cm}$ - thick & 0.33 \\
\hline R4 - Insulation $12 \mathrm{~cm}$ - thick & 0.28 \\
\hline R4 - Insulation $15 \mathrm{~cm}$ - thick & 0.23 \\
\hline
\end{tabular}

Comparing the results using $15 \mathrm{~cm}$-thick insulation with the original state of the building, an increase of around 8.5\% was achieved for the comfort rate considering the static approach. For the adaptive method, the improvement is higher, with an increase of around $14.5 \%$ of the comfort rate, also achieving a significant decrease in the overheating rate $(-11 \%)$. Nonetheless, it is important to note that with the use of insulation of $1 \mathrm{~cm}$ and $3 \mathrm{~cm}$ thick the comfort rate increase around $1.4 \%$ in both cases, but for the following insulation thicknesses the improvements become lower, being the difference in the comfort rate of around 1\% between the results employing $5 \mathrm{~cm}$-thick and $15 \mathrm{~cm}$-thick insulation. Figure 12c depicts the results regarding cooling and heating needs, where the same trend 
that for the comfort rates are recorded. Also, it is indicated that for an insulation thickness of $8 \mathrm{~cm}$ to $15 \mathrm{~cm}$ the differences between the results are not too meaningful.

(a) ROOF 4 - Fixed Range

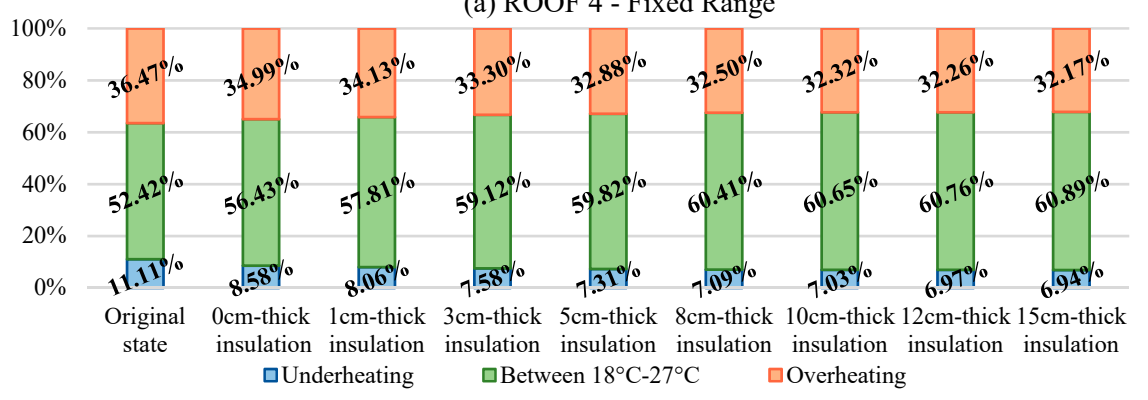

(b) ROOF 4 - Category II

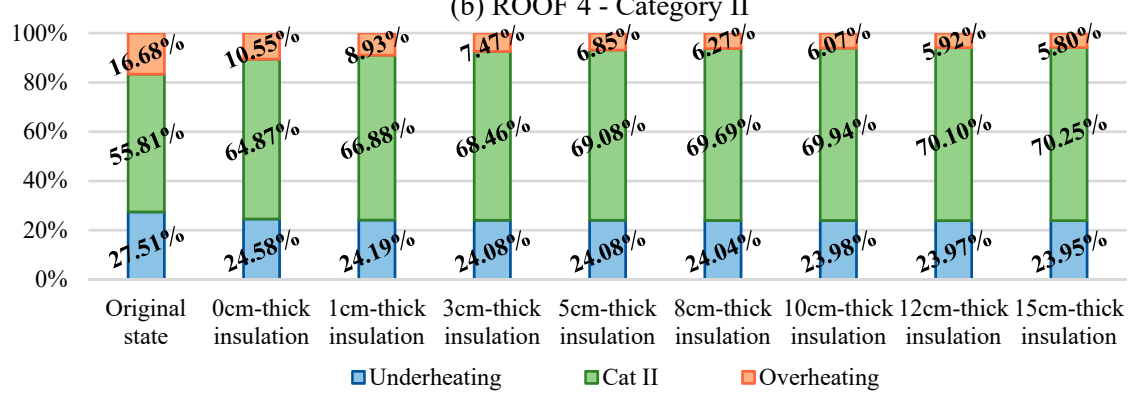

(c) Annual energy requirement - R4

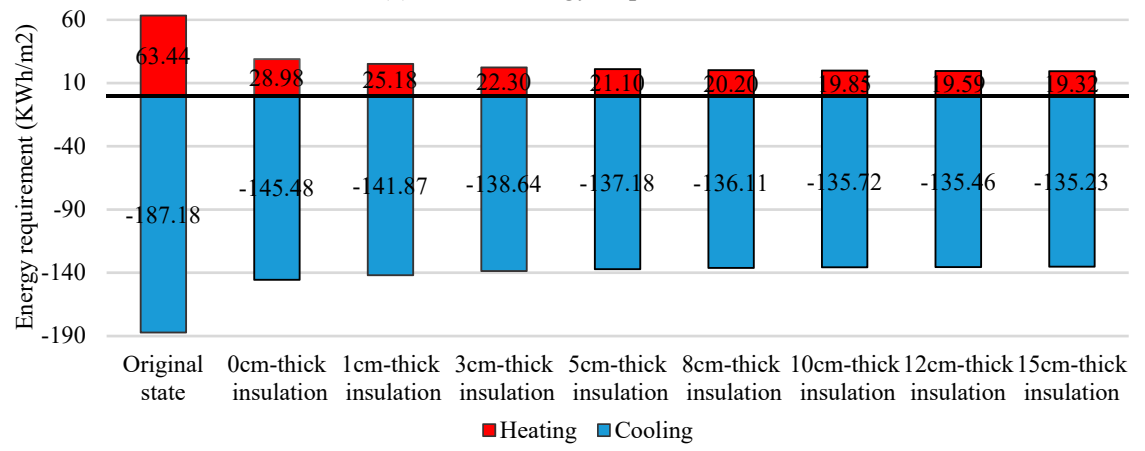

Figure 12. Comfort rates according to the static (a) and the adaptive (b) approach and annual energy requirement (c) for the roof $\mathrm{R} 4$ according to different insulation thicknesses.

\subsection{Evaluation of Different Insulation Thicknesses for Walls}

For the walls, five insulation thicknesses were considered. Furthermore, considering that the most widely used wall thickness in the country is currently $15 \mathrm{~cm}$ thick, three different wall thicknesses were evaluated without insulation materials, including the $15 \mathrm{~cm}$ wall. Thus, several simulations were performed taking as a base the original state of the building and intervening one exterior wall at a time, considering each orientation. For the SW orientation, Table 11 shows the thermal transmittance of the walls simulated, and Figure 13 depicts the results in terms of comfort rates and energy requirement. 
Table 11. Thermal transmittance of wall W2 with SW orientation according to the insulation thickness used.

\begin{tabular}{lc}
\hline Description & $\mathbf{U}\left(\mathbf{W} / \mathbf{m}^{2} \mathbf{K}\right)$ \\
\hline W1a $-15 \mathrm{~cm}$-thick & 2.97 \\
\hline W1a - Original state & 2.53 \\
\hline W1a - 30 cm-thick & 1.95 \\
\hline W2a - Insulation $1 \mathrm{~cm}$-thick & 1.49 \\
\hline W2a - Insulation $3 \mathrm{~cm}$-thick & 0.86 \\
\hline W2a - Insulation $5 \mathrm{~cm}$-thick & 0.60 \\
\hline W2a - Insulation $8 \mathrm{~cm}$-thick & 0.41 \\
\hline W2a - Insulation $10 \mathrm{~cm}$-thick & 0.34 \\
\hline
\end{tabular}

(a) WALL SW orientation - Fixed Range

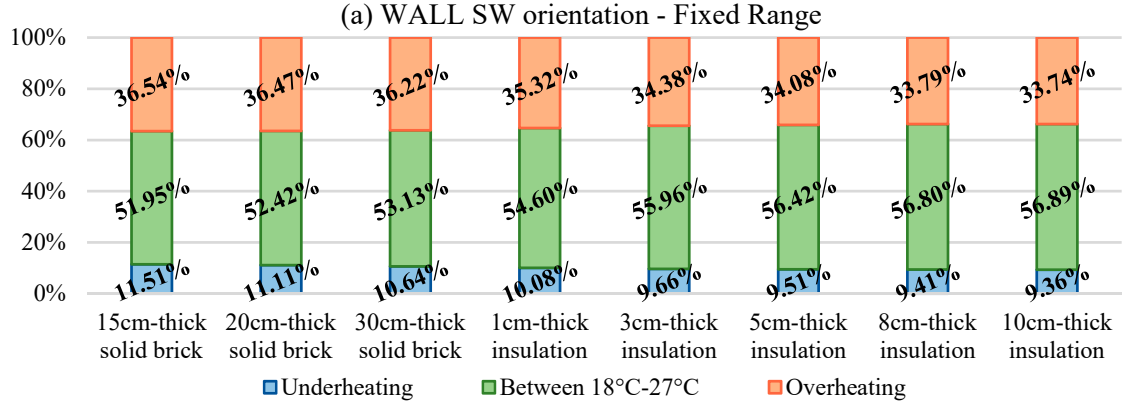

(b) WALL SW orientation- Category II
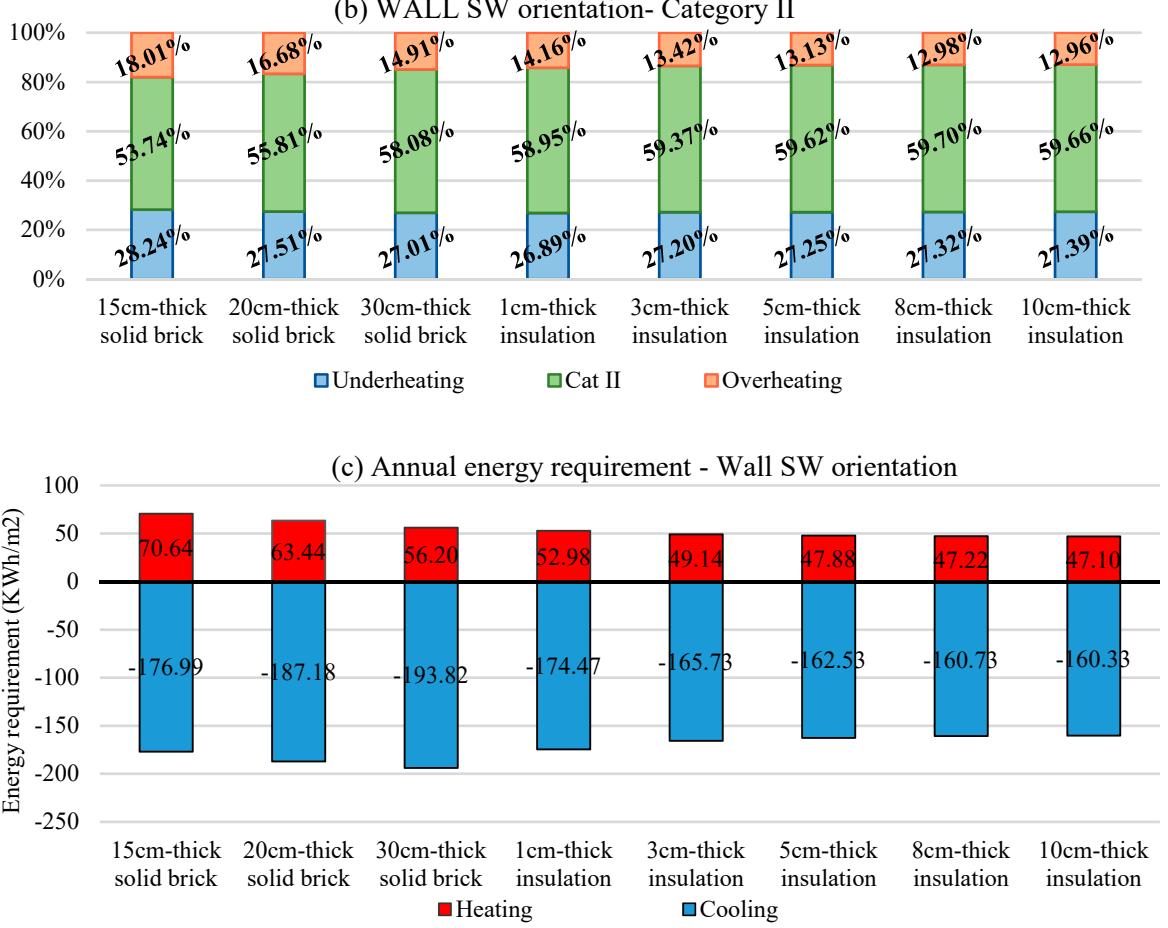

Figure 13. Comfort rates according to the static (a) and the adaptive (b) approach and annual energy requirement (c) for the wall W2 with SW orientation according to different insulation thicknesses.

As expected, the lowest comfort rate was delivered for the most widely used wall thickness in the country $(15 \mathrm{~cm})$, nonetheless, with the addition of $3 \mathrm{~cm}$-thick insulation material only on the wall with SW orientation the comfort rate can increase around $4 \%$ considering the static approach and $5.63 \%$ considering the adaptive method. Also, it is recorded that for an insulation thickness of $5 \mathrm{~cm}$ to 
$10 \mathrm{~cm}$ the differences between the results are not very significant. Regarding the energy requirement (Figure 13c), the results for the heating needs follow the same trend of the comfort rates.

For the cooling needs, the highest value was recorded for the $30 \mathrm{~cm}$ thick wall, followed by the $20 \mathrm{~cm}$ and $15 \mathrm{~cm}$ thick, respectively. As the cooling needs are being considered in this research in terms of the zone sensible cooling, which is, as previously referred, the overall cooling contribution to the heat balance of the thermal zone under analysis from the cooling system. So, the values for the cooling needs are influenced by the heat transfer involved in all building components. With the $15 \mathrm{~cm}$-thick wall is recorded the higher discomfort rates, which indicates a lower gradient temperature since the thermal zone presents conditions more similar to the outdoor conditions. So, this lower gradient temperature translates to lower heat transfer values decreasing the values of the cooling thermal loads. Furthermore, with a thinner wall, the component is able to gain and lose heat on an equal basis. Nonetheless, with the use of insulation, the energy requirement decreased significantly, achieving a reduction of around $11.4 \%$ of the cooling needs and $22.5 \%$ of the heating needs with the use of $3 \mathrm{~cm}$ thick insulation only in the wall with SW orientation, and regarding the original state of the building ( $20 \mathrm{~cm}$ thick).

For the NW orientation, Table 12 shows the thermal transmittance of the walls simulated, and Figure 14 depicts the results regarding comfort rates and energy requirement. Comparing the results between the two orientations, the results suggest that the wall with SW orientation has a higher incident on the comfort rates since higher values within the comfort zone were obtained with the intervention in the SW wall. Thus, it is more effective to intervene walls on the SW orientation. Regarding the comfort rates and energy requirement, the same trend of the wall on the SW orientation are recorded, but with lower values for the improvements since with the use of $3 \mathrm{~cm}$ thick insulation the comfort rate increased $1.27 \%$ for the static method and the heating and cooling needs decreased around $11 \%$ and $6 \%$, respectively.

Table 12. Thermal transmittance of wall W2 with NW orientation according to the insulation thickness used.

\begin{tabular}{cc}
\hline Description & $\mathbf{U}\left(\mathbf{W} / \mathbf{m}^{2} \mathbf{K}\right)$ \\
\hline $\mathrm{W} 1 \mathrm{~b}-15 \mathrm{~cm}$-thick & 2.97 \\
\hline $\mathrm{W} 1 \mathrm{~b}-20 \mathrm{~cm}$-thick & 2.53 \\
\hline $\mathrm{W} 1 \mathrm{~b}$ - Original state & 1.95 \\
\hline $\mathrm{W} 2 \mathrm{~b}$ - Insulation $1 \mathrm{~cm}$-thick & 1.27 \\
\hline $\mathrm{W} 2 \mathrm{~b}$ - Insulation $3 \mathrm{~cm}$-thick & 0.77 \\
\hline $\mathrm{W} 2 \mathrm{~b}$ - Insulation $5 \mathrm{~cm}$-thick & 0.56 \\
\hline $\mathrm{W} 2 \mathrm{~b}$ - Insulation $8 \mathrm{~cm}$-thick & 0.39 \\
\hline $\mathrm{W} 2 \mathrm{~b}$ - Insulation $10 \mathrm{~cm}$-thick & 0.33 \\
\hline
\end{tabular}

(a) WALL NW orientation - Fixed Range

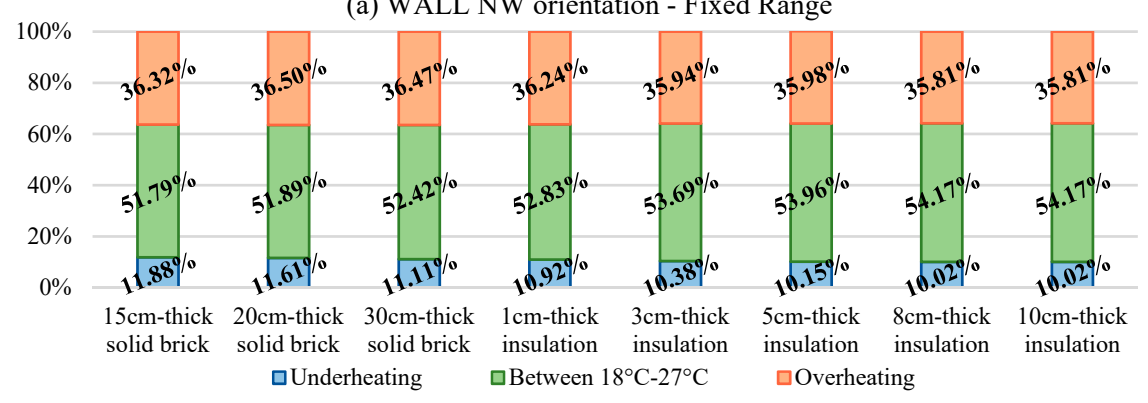

Figure 14. Cont. 
(b) WALL NW orientation- Category II

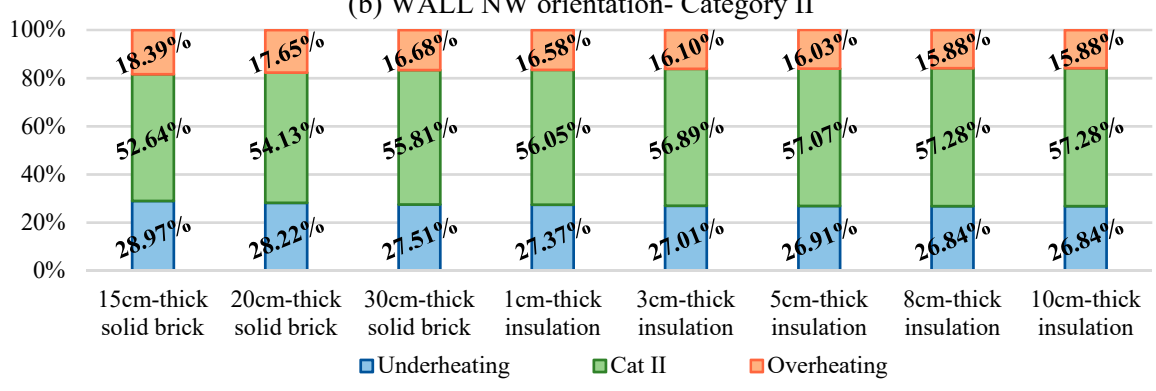

(c) Annual energy requirement - Wall NW orientation

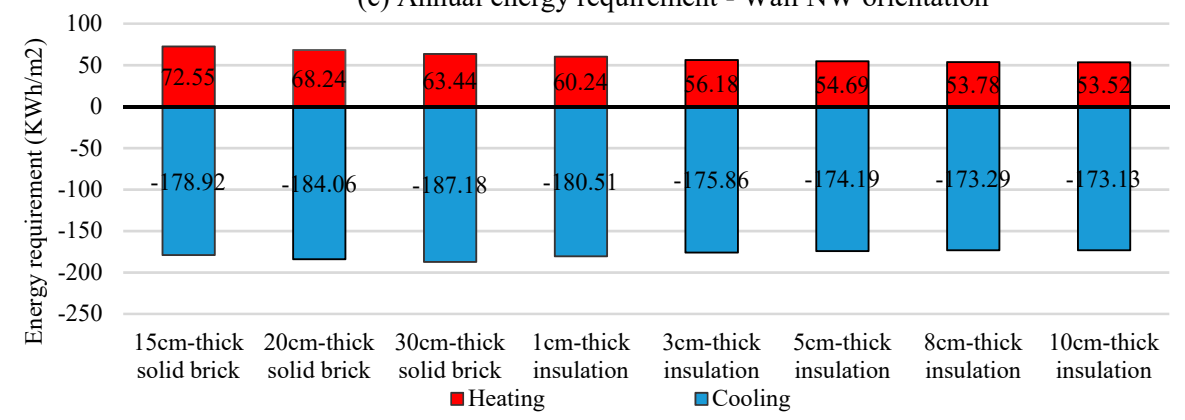

Figure 14. Comfort rates according to the static (a) and the adaptive (b) approach and annual energy requirement (c) for the wall W2 with NW orientation according to different insulation thicknesses.

\subsection{Application of the AHP method to choose the most recommended insulation thickness}

Once all the simulations were evaluated, the AHP method was applied to find the most recommended insulation thickness. The same considerations previously described for the method were employed, and the pairwise comparison matrix of criteria used are depicted in Tables 6 and 7. For the criteria, the weights were allocated considering the results obtained from the simulations for comfort rates and cooling needs, and the costs involved for each intervention are depicted in Table 13. Thus, the calculation of weight for each alternative and criterion was made, and the results from the combined synthesis model are illustrated in Table 14. In general, the most recommended insulation thicknesses are $3 \mathrm{~cm}, 5 \mathrm{~cm}$ and $8 \mathrm{~cm}$, for both roofs and walls, followed by the options employing higher insulation thicknesses. In none case, the walls without the use of insulation materials recorded a good overall weight, which had the last places in the ranking for all the alternatives.

Table 13. Costs involved for each alternative under consideration.

\begin{tabular}{cccccc}
\hline Roof & \multicolumn{2}{c}{ Wall SW Orientation } & \multicolumn{2}{c}{ Wall NW Orientation } \\
\hline Alternative & Costs & Alternative & Costs & Alternative & Costs \\
\hline R1 - Original & 1.00 & W1a-15 cm & 0.72 & W1b-15 cm & 0.58 \\
R4-0 cm & 1.34 & W1a-20 cm & 1.00 & W1b-20 cm & 0.80 \\
R4-1 cm & 1.36 & W1a-30 cm & 1.25 & W1b-30 cm & 1.00 \\
R4-3 cm & 1.37 & W2a-1 cm & 1.07 & W2b-1 cm & 1.05 \\
R4-5 cm & 1.38 & W2a-3 cm & 1.09 & W2b-3 cm & 1.07 \\
R4-8 cm & 1.40 & W2a-5 cm & 1.13 & W2b-5 cm & 1.10 \\
R4-10 cm & 1.41 & W2a-8 cm & 1.18 & W2b-8 cm & 1.15 \\
R4-12 cm & 1.44 & W2a-10 cm & 1.21 & W2b-10 cm & 1.17 \\
R4-15 cm & 1.46 & & & & \\
\hline
\end{tabular}


Table 14. Global priority vector for different insulation thicknesses.

\begin{tabular}{ccccccccc}
\hline Roof & \multicolumn{3}{c}{ Wall SW Orientation } & \multicolumn{3}{c}{ Wall NW Orientation } \\
\hline Alternative & Weight & Rank & Alternative & Weight & Rank & Alternative & Weight & Rank \\
\hline R1 - Original & 0.076 & 9 & W1a-15 cm & 0.110 & 6 & W1b-15 cm & 0.143 & 5 \\
R4-0 cm & 0.080 & 8 & W1a-20 cm & 0.079 & 7 & W1b-20 cm & 0.091 & 7 \\
R4-1 cm & 0.114 & 7 & W1a-30 cm & 0.075 & 8 & W1b-30 cm & 0.066 & 8 \\
R4-3 cm & 0.122 & 3 & W2a-1 cm & 0.124 & 5 & W2b-1 cm & 0.092 & 6 \\
R4-5 cm & 0.125 & 2 & W2a-3 cm & 0.154 & 2 & W2b-3 cm & 0.157 & 2 \\
R4-8 cm & 0.133 & 1 & W2a-5 cm & 0.162 & 1 & W2b-5 cm & 0.159 & 1 \\
R4-10 cm & 0.118 & 4 & W2a-8 cm & 0.149 & 3 & W2b-8 cm & 0.147 & 3 \\
R4-12 cm & 0.117 & 5 & W2a-10 cm & 0.148 & 4 & W2b-10 cm & 0.145 & 4 \\
R4-15 cm & 0.116 & 6 & & & & & & \\
\hline
\end{tabular}

\subsection{Thermal Performance Evaluation of the Energy Efficiency Version of the Building}

The next step is to simulate the whole building considering the improvements for the roofs and walls together. Thus, for this section an insulation thickness of $5 \mathrm{~cm}$ for the roof and $3 \mathrm{~cm}$ for the walls is evaluated. The results regarding comfort rates and energy requirement are depicted in Figure 15. It can be seen that the overheating and underheating rates have significantly decreased, in fact, considering the adaptive method the building is overheated only $2.71 \%$ of the year. In general, the adaptive method tends to be permissive with higher temperatures but not with lower temperatures, delivering an underheating rate of $20.95 \%$. However, with the static approach, it demonstrates that the building is under $18{ }^{\circ} \mathrm{C}$ only $3.76 \%$ of the year. Regarding the energy requirement, the heating needs per square meter decreased $85 \%$ regarding the original state of the building and the cooling needs decreased around $45 \%$, having now a value of $104 \mathrm{KWh} / \mathrm{m}^{2}$.

(a) Comfort rates

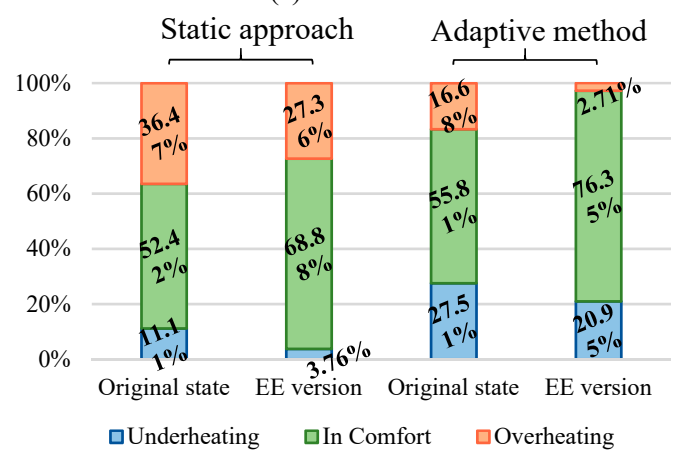

(b) Energy requirement

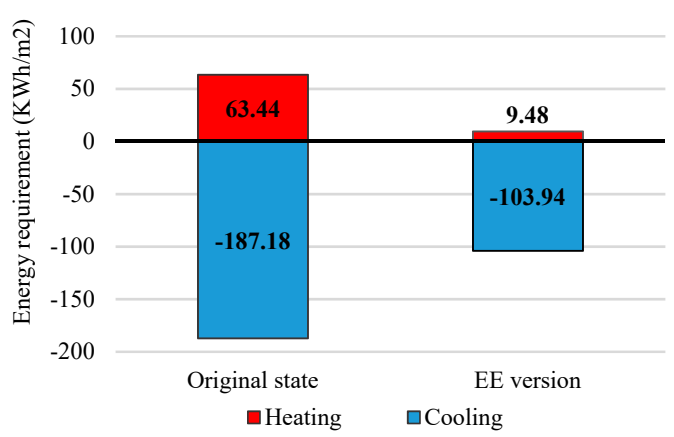

Figure 15. Results of the energy efficiency version of the building.

Once obtained the energy efficiency version of the building in its original orientation, the building was rotated $180^{\circ}$ to run others annual simulations and to evaluate the changes in the comfort rates. Different insulation thicknesses were considered, for both roofs and walls, and the results are depicted in Figure 16. It can be seen that with this orientation (southeast) the thermal zone has a slightly better response regarding overheating rates, the underheating rates instead had a little increase, which was expected considering that there is not a direct solar incident during winter season with this orientation, and for the summertime only impinges the morning sun radiation. Thus, to achieve a thermal performance similar to which the building had in its original orientation for the colder season is necessary to increase the insulation thickness. Nonetheless, the annual comfort rate is higher with this orientation due to the improvements for the summer season. 

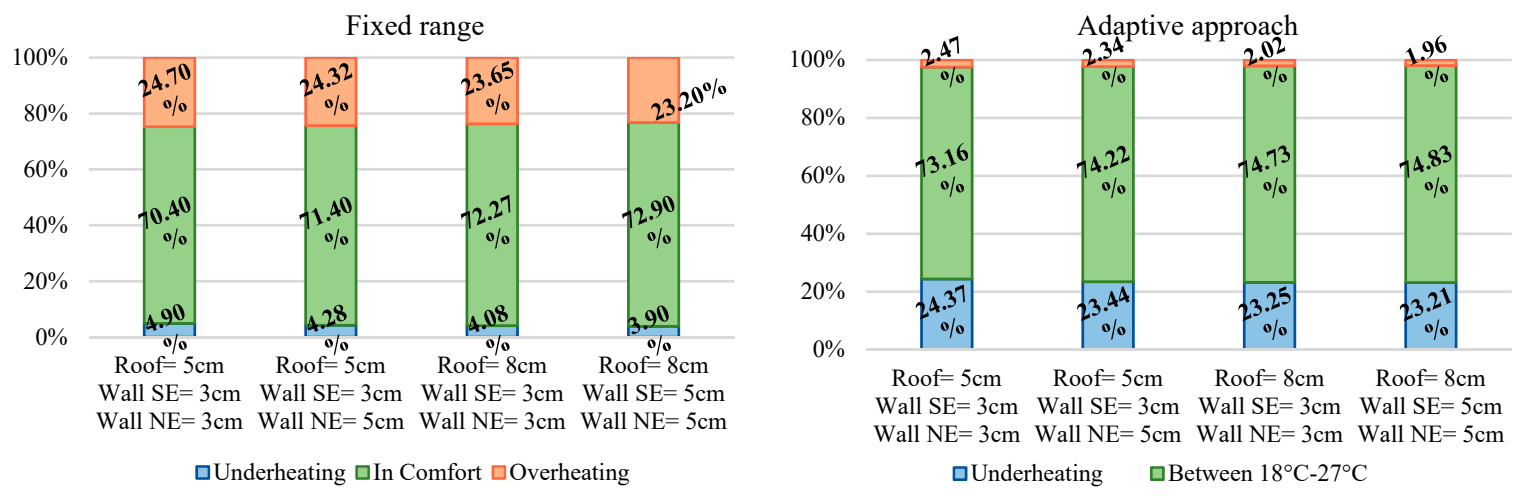

Figure 16. Simulations results of the building rotated $180^{\circ}$.

\subsection{Evaluation of Different Window-to-Wall Ratios According to Orientation}

Finally, the last target of this study is to evaluate different WWR for the thermal zone under analysis according to each orientation and taking as a base the energy efficiency version of the building. Four different WWR were evaluated on each orientation, with and without the use of shading systems, and the results regarding comfort rates employing the static approach are depicted in Figure 17. It was recorded that the use of shading systems can increase by around $2.6 \%$ on average the comfort rates considering all the WWR used, being this rate higher as the WWR increases.

As expected, as the WWR increase the discomfort rates also increase. The lowest comfort rates were delivered on the SW orientation, being thus not recommended to use large glazing areas on this orientation. Increasing the WWR to $15 \%$ on the SE or NE orientation, the thermal zone presents a slightly better thermal performance regarding the energy efficiency version of the building employing the original WWR $(8.7 \%)$. Even though the underheating rates increased slightly, the addition of extra glazing areas allowed to enhance the natural ventilation rates during night-time improving the indoor temperatures. Nonetheless, for higher WWR ratios this feature is not repeated.

(a) $\mathrm{WWR}=15 \%$

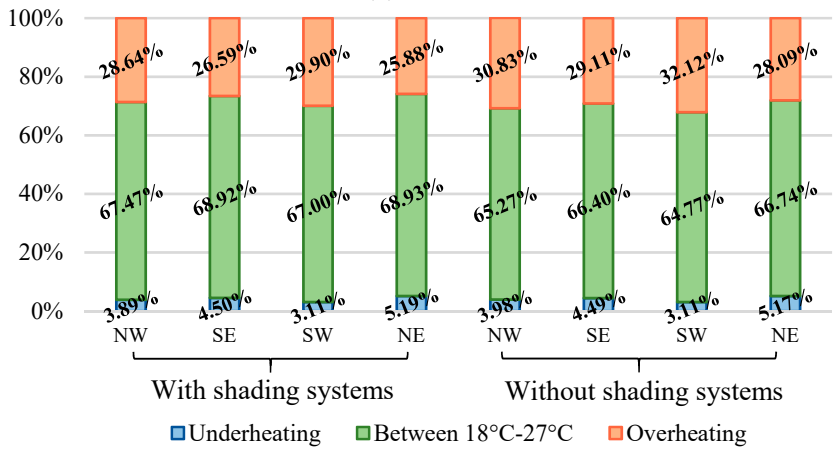

(b) $\mathrm{WWR}=20 \%$

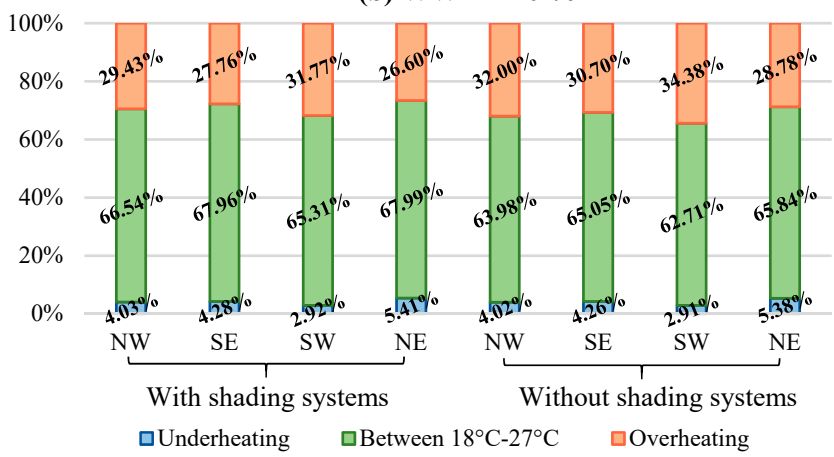

Figure 17. Cont. 
(c) $W W R=25 \%$

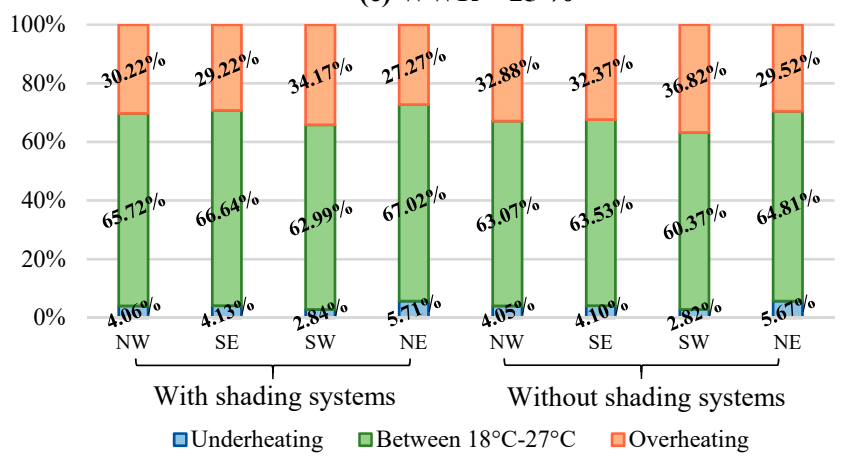

(d) $\mathrm{WWR}=30 \%$

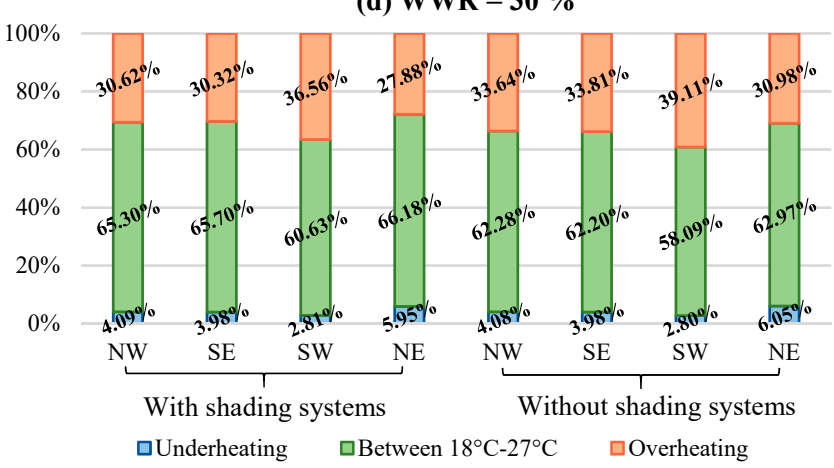

Figure 17. Comfort rates varying according to different WWR by orientation with and without the use of shading systems.

\section{Conclusions}

In this paper, a parametric study of several energy retrofit solutions for buildings is developed in order to analyse their efficiency in terms of comfort rates and cooling needs. For this purpose, more than 130 annual dynamic energy simulations of the building were performed. Furthermore, the Analytic Hierarchy Process is employed as a decision-making method to choose the most convenient intervention considering the investment costs required.

Regarding the AHP method, it can be said that it has a clear structure that facilitates its application to any decision problem. Also, it allows controlling the weights assignment of criteria through the consistency ratio, which gives some robustness to the analysis providing an acceptable approximation to the expected results. However, its main weakness would be the high subjectivity with which the analysis is established since the allocation of weights for each criterion/alternative could be decisive when setting the best alternative. Furthermore, this subjectivity can lead to some inconsistencies in the final comparison matrices. Nonetheless, consistency ratios lower than 0.10 , as the used in this research, allows validating the AHP analysis. Thus, after the sensitivity analysis of the results and the performance evaluation, the following conclusions can be stated:

- If the glazing areas are not significant (WWR lower than $10 \%$ ), the intervention may not be justified since the incidence of glazing areas on thermal comfort and energy requirement is not meaningful, but not so, the costs involved in the interventions.

- With the intervention on the roof, the annual discomfort rates can decrease by $7.4 \%$ for the static approach, and the annual energy requirement can decrease by around $37 \%$ regarding the original state of the building. The AHP analysis suggests that the best option is the configuration R4, followed by the R3 and finally the R2, even though the costs differences among the alternatives were not significant, the differences in terms of comfort rates and cooling needs influence the results. 
- With the intervention on the walls, the higher comfort rates were recorded by the configurations employing exterior claddings. In fact, an increase of almost $7 \%$ in the annual comfort rate can be achieved with an exterior reinforcement of exterior walls with $5 \mathrm{~cm}$ insulation. The AHP analysis suggests that the configurations employing exterior and inner insulation plus a layer of plaster represents the best options since they delivered a good thermal performance at lower costs, besides allowing a greater indoor useful area of the thermal zone under analysis.

- Regarding the insulation thicknesses, in general, the most recommended insulation thicknesses are $3 \mathrm{~cm}, 5 \mathrm{~cm}$ and $8 \mathrm{~cm}$, for both roofs and walls, employing an insulation material with $0.04 \mathrm{~W} / \mathrm{m} . \mathrm{K}$ of thermal conductivity. This means that for roofs, a thermal transmittance value between $0.79-0.34 \mathrm{~W} / \mathrm{m}^{2} \mathrm{~K}$ is recommended. For walls with an SW and NE orientation, those values between $0.86-0.41 \mathrm{~W} / \mathrm{m}^{2} \mathrm{~K}$ and for walls with an NW and SE orientation the values between $0.77-0.39 \mathrm{~W} / \mathrm{m}^{2} \mathrm{~K}$ (Table 15 ).

- Concerning window to wall ratios, a WWR up to $15 \%$ on the SE or NE orientation, with the use of shading systems, can help to increase natural ventilation rates improving comfort rates. Nonetheless, higher values of WWR can increase the overheating rates significantly, and this increase is accentuated without the use of shading systems, and mainly for glazing areas located on SW orientations.

Table 15. Threshold values of thermal transmittance recommended.

\begin{tabular}{lc}
\hline Building Component & Recommended Values of Thermal Transmittance $U\left(\mathbf{W} / \mathbf{m}^{\mathbf{2}} \mathbf{K}\right)$ \\
\hline Roofs & $0.79-0.34$ \\
Walls SW and NE & $0.86-0.41$ \\
Walls NW and SE & $0.77-0.39$ \\
\hline
\end{tabular}

The general objective of this research was to establish threshold values of thermal transmittance for the building thermal envelope components, in order to contribute to the regulation of thermal parameters to improve the energy efficiency of Paraguayan buildings. Even though some researchers highlight the importance of combining software tools with sensors for the evaluation of building thermal performance [39,40], real in situ measurements were not possible to develop for the present research work. This is because the building taken as a case study is a private family dwelling and the blueprints were obtained through the local municipality, ensuring privacy and confidentiality. In addition, this work was developed in Europe very far from the building location.

Nonetheless, considering that currently Paraguay has no thermal and energy regulations for buildings, concerted efforts were made to use as a case study a building and the climate of Paraguay, with the objective of contributing to the future energy regulations of the country, demonstrating the importance and effectiveness of energy retrofit solutions to improve thermal performance of buildings, having thus an important impact on country's sustainability. Considering this, one of the main objectives for further research in this area for the country is the validation and calibration of the presented model through monitorisation and in situ measurements at the building location.

It is important to highlight that the simulations tools employed in this research are highly recommended by several international and renowned standards, which have been greatly used in several scientific investigations [41-46]. Accordingly, the simulation tools accuracy supports the results reliability of the energy efficiency of the building in its original state, without thermal insulation materials, and the results of the energy efficient version, demonstrating thus the effectiveness of the strategies implemented for the climate under analysis.

The results of this paper have demonstrated that passive energy retrofit strategies are effective for the climate under analysis and can significantly reduce the energy requirement of the building sector through the improvement of annual comfort rates. This is a sustainable approach being the building performance and the user's comfort independent from the energy costs fluctuation. Furthermore, 
the results herein presented can serve as support and contribute to the regulation of thermal parameters aiding to improve the energy efficiency of Paraguayan buildings.

Author Contributions: Conceptualization, F.S.; Methodology, F.S., F.R. and S.M.; Investigation, F.S.; Resources, F.S., F.R.; Writing-Original Draft Preparation, F.S.; Writing—Review \& Editing, F.S., F.R. and S.M.; Supervision, F.R. and S.M.

Funding: This project has been funded with support of the European Commission and reflects the view only of the author. The Commission cannot be held responsible for any use which may be made of the information contained therein-ELARCH program (Project Reference number: 552129-EM-1-2014-1-IT-ERA MUNDUS-EMA21).

Conflicts of Interest: The authors declare no conflict of interest.

\section{References}

1. Nematchoua, M.K.; Raminosoa, C.R.R.; Mamiharijaona, R.; René, T.; Orosa, J.A.; Elvis, W.; Meukam, P. Study of the Economical and Optimum Thermal Insulation Thickness for Buildings in a Wet and Hot Tropical Climate: Case of Cameroon. Renew. Sustain. Energy Rev. 2015, 50, 1192-1202. [CrossRef]

2. Kolaitis, D.I.; Malliotakis, E.; Kontogeorgos, D.A.; Mandilaras, I.; Katsourinis, D.I.; Founti, M.A. Comparative Assessment of Internal and External Thermal Insulation Systems for Energy Efficient Retrofitting of Residential Buildings. Energy Build. 2013, 64, 123-131. [CrossRef]

3. Noailly, J. Improving the Energy Efficiency of Buildings: The Impact of Environmental Policy on Technological Innovation. Energy Econ. 2012, 34, 795-806. [CrossRef]

4. Verbeke, S.; Audenaert, A. Thermal Inertia in Buildings: A Review of Impacts across Climate and Building Use. Renew. Sustain. Energy Rev. 2017, 82, 2300-2318. [CrossRef]

5. Kumar, A.; Sah, B.; Singh, A.R.; Deng, Y.; He, X.; Kumar, P.; Bansal, R.C. A Review of Multi Criteria Decision Making (MCDM) towards Sustainable Renewable Energy Development. Renew. Sustain. Energy Rev. 2017, 69, 596-609. [CrossRef]

6. Wang, J.J.; Jing, Y.Y.; Zhang, C.F.; Zhao, J.H. Review on Multi-Criteria Decision Analysis Aid in Sustainable Energy Decision-Making. Renew. Sustain. Energy Rev. 2009, 13, 2263-2278. [CrossRef]

7. Saaty, T. How to Make a Decision: The Analytic Hierarchy Process. Eur. J. Oper. Res. 1990, 48, 9-26. [CrossRef]

8. Kablan, M.M. Decision Support for Energy Conservation Promotion: An Analytic Hierarchy Process Approach. Energy Policy 2004, 32, 1151-1158. [CrossRef]

9. Mu, E.; Pereyra-Rojas, M. Understanding the Analytic Hierarchy Process. In Practical Decision Making; SpringerBriefs in Operations Research; Springer: Berlin, Germany, 2017.

10. Khalil, N.; Kamaruzzaman, S.N.; Baharum, M.R. Ranking the Indicators of Building Performance and the Users' Risk via Analytical Hierarchy Process (AHP): Case of Malaysia. Ecol. Indic. 2016, 71, 567-576. [CrossRef]

11. Kamaruzzaman, S.N.; Lou, E.C.W.; Wong, P.F.; Wood, R.; Che-Ani, A.I. Developing Weighting System for Refurbishment Building Assessment Scheme in Malaysia through Analytic Hierarchy Process (AHP) Approach. Energy Policy 2018, 112, 280-290. [CrossRef]

12. Kuzman, M.K.; Grošelj, P.; Ayrilmis, N.; Zbašnik-Senegačnik, M. Comparison of Passive House Construction Types Using Analytic Hierarchy Process. Energy Build. 2013, 64, 258-263. [CrossRef]

13. Kljajić, M.; Andelković, A.S.; Mujan, I. Assessment of Relevance of Different Effects in Energy Infrastructure Revitalization in Non-Residential Buildings. Energy Build. 2016, 116, 684-693. [CrossRef]

14. Liu, K.S.; Hsueh, S.L.; Wu, W.C.; Chen, Y.L. A DFuzzy-DAHP Decision-Making Model for Evaluating Energy-Saving Design Strategies for Residential Buildings. Energies 2012, 5, 4462-4480. [CrossRef]

15. Lee, S.K.; Yoon, Y.J.; Kim, J.W. A Study on Making a Long-Term Improvement in the National Energy Efficiency and GHG Control Plans by the AHP Approach. Energy Policy 2007, 35, 2862-2868. [CrossRef]

16. Yang, Y.; Li, B.; Yao, R. A Method of Identifying and Weighting Indicators of Energy Efficiency Assessment in Chinese Residential Buildings. Energy Policy 2010, 38, 7687-7697. [CrossRef]

17. Garbuzova-Schlifter, M.; Madlener, R. AHP-Based Risk Analysis of Energy Performance Contracting Projects in Russia. Energy Policy 2016, 97, 559-581. [CrossRef]

18. Mirjat, N.H.; Uqaili, M.A.; Harijan, K.; Mustafa, M.W.; Rahman, M.M.; Khan, M.W.A. Multi-Criteria Analysis of Electricity Generation Scenarios for Sustainable Energy Planning in Pakistan. Energies 2018, 11, 1-33. [CrossRef] 
19. Saaty, R.W. The Analytic Hierarchy Process-What It Is and How It Is Used. Math. Model. 1987, 9, 161-176. [CrossRef]

20. Saaty, T.L. Relative Measurement and Its Generalization in Decision Making Why Pairwise Comparisons Are Central in Mathematics for the Measurement of Intangible Factors the Analytic Hierarchy/Network Process. Rev. Real Acad. Cienc. Exactas, Físicas Nat. Ser. A Mat. 2008, 102, 251-318. [CrossRef]

21. DesignBuilder Software Ltd. DesignBuilder EnergyPlus Simulation Documentation for DesignBuilder V5; DesignBuilder Software Ltd.: Stroud, UK, 2015.

22. European Committee for Standardization (CEN). EN 15251: Indoor Environmental Input Parameters for the Design and Assessment of Energy Performance of Buildings; STD Version 2.1c; European Comission: Brussels, Belgium, 2014; pp. 1-81.

23. Carlucci, S.; Bai, L.; de Dear, R.; Yang, L. Review of Adaptive Thermal Comfort Models in Built Environmental Regulatory Documents. Build. Environ. 2018, 137, 73-89. [CrossRef]

24. Alves, C.A.; Duarte, D.H.S.; Gonçalves, F.L.T. Residential Buildings' Thermal Performance and Comfort for the Elderly under Climate Changes Context in the City of São Paulo, Brazil. Energy Build. 2016, 114, 62-71. [CrossRef]

25. Figueiredo, A.; Figueira, J.; Vicente, R.; Maio, R. Thermal Comfort and Energy Performance: Sensitivity Analysis to Apply the Passive House Concept to the Portuguese Climate. Build. Environ. 2016, 103, 276-288. [CrossRef]

26. Roetzel, A.; Tsangrassoulis, A. Impact of Climate Change on Comfort and Energy Performance in Offices. Build. Environ. 2012, 57, 349-361. [CrossRef]

27. Figueiredo, A.; Vicente, R.; Lapa, J.; Cardoso, C.; Rodrigues, F.; Kämpf, J. Indoor Thermal Comfort Assessment Using Different Constructive Solutions Incorporating PCM. Appl. Energy 2017, 208, 1208-1221. [CrossRef]

28. Roetzel, A.; Tsangrassoulis, A.; Dietrich, U. Impact of Building Design and Occupancy on Office Comfort and Energy Performance in Different Climates. Build. Environ. 2014, 71, 165-175. [CrossRef]

29. Rubio-Bellido, C.; Pérez-Fargallo, A.; Pulido-Arcas, J.A.; Trebilcock, M. Application of Adaptive Comfort Behaviors in Chilean Social Housing Standards under the Influence of Climate Change. Build. Simul. 2017, 10, 933-947.

30. Ministerio da Economia e do Emprego. Decreto Lei $N^{\circ} 118 / 2013$ de 20 de Agosto—Regulamento de Desempenho Energetico Dos Edifícios de Habitaçao (REH); Diario de la Republica, N 159 1ra Serie.: Lisboa, Portugal, 2013; pp. 4988-5005.

31. Ministerio de Vivienda y Urbanismo del Gobierno de Chile. Estándares de Construcción Sustentable Para Viviendas de Chile, Tomo I: Salud y Bienestar, 2nd ed.; División Técnica de Estudio y Fomento Habitacional, Ed.; Ministerio de Vivienda y Urbanismo: Santiago, Chile, 2018.

32. Brazilian Association of Technical Standards (ABNT). NBR 16401:2008 Instalações de Ar-Condicionado-Sistemas Centrais e Unitários-Parte 2: ParâMetros de Conforto Térmico; Associação Brasileira de Normas Técnicas: Rio de Janeiro, Brazil, 2008.

33. Chartered Institution of Building Services Engineers (CIBSE). Environmental Design, 7th ed.; CIBSE: London, UK, 2006. [CrossRef]

34. Lu, S.; Pang, B.; Qi, Y.; Fang, K. Field Study of Thermal Comfort in Non-Air-Conditioned Buildings in a Tropical Island Climate. Appl. Ergon. 2018, 66, 89-97. [CrossRef]

35. Djamila, H. Indoor Thermal Comfort Predictions: Selected Issues and Trends. Renew. Sustain. Energy Rev. 2017, 74, 569-580. [CrossRef]

36. López, V.; Lucchese, J.R.; Andreasi, W.A. Thermal Comfort Assessment in the Hot and Humid Region of Paraguay: A Comparison Between Three Methodologies. Int. J. Civ. Environ. Eng. 2015, 15, $26-31$.

37. Wankanapon, P.; Mistrick, R.G. Roller Shades and Automatic Lighting Control with Solar Radiation Control Strategies. Built 2011, 1, 35-42.

38. Alwetaishi, M. Impact of Glazing to Wall Ratio in Various Climatic Regions: A Case Study. J. King Saud Univ. Eng. Sci. 2018, 1-13. [CrossRef]

39. Melgar, S.G.; Bohórquez, M.Á.M.; Márquez, J.M.A. UhuMEB: Design, Construction, and Management Methodology of Minimum Energy Buildings in Subtropical Climates. Energies 2018, 11, 2745. [CrossRef]

40. Asdrubali, F.; Buratti, C.; Cotana, F.; Baldinelli, G.; Goretti, M.; Moretti, E.; Baldassarri, C.; Belloni, E.; Bianchi, F.; Rotili, A.; et al. Evaluation of Green Buildings' Overall Performance through in Situ Monitoring and Simulations. Energies 2013, 6, 6525-6547. [CrossRef] 
41. Auzeby, M.; Wei, S.; Underwood, C.; Tindall, J.; Chen, C.; Ling, H.; Buswell, R. Effectiveness of Using Phase Change Materials on Reducing Summer Overheating Issues in UK Residential Buildings with Identification of Influential Factors. Energies 2016, 9, 605. [CrossRef]

42. Rospi, G.; Cardinale, N.; Negro, E. Energy Performance and Economic Feasibility Study of Historical Building in the City of Matera, Southern Italy. Energies 2017, 10, 2009. [CrossRef]

43. Rey-Hernández, J.M.; Velasco-Gómez, E.; San José-Alonso, J.F.; Tejero-González, A.; Rey-Martínez, F.J. Energy Analysis at a near Zero Energy Building. A Case-Study in Spain. Energies 2018, 11, 857. [CrossRef]

44. Lin, Y.; Zhou, S.; Yang, W.; Shi, L.; Li, C.Q. Development of Building Thermal Load and Discomfort Degree Hour Prediction Models Using Data Mining Approaches. Energies 2018, 11, 1570. [CrossRef]

45. Bhandari, M.; Hun, D.; Shrestha, S.; Pallin, S.; Lapsa, M. A Simplified Methodology to Estimate Energy Savings in Commercial Buildings from Improvements in Airtightness. Energies 2018, 11, 3322. [CrossRef]

46. Yu, S.; Cui, Y.; Shao, Y.; Han, F. Research on the Comprehensive Performance of Hygroscopic Materials in an Office Building Based on EnergyPlus. Energies 2019, 12, 191. [CrossRef]

(C) 2019 by the authors. Licensee MDPI, Basel, Switzerland. This article is an open access article distributed under the terms and conditions of the Creative Commons Attribution (CC BY) license (http:/ / creativecommons.org/licenses/by/4.0/). 